Portland State University

PDXScholar

\title{
An Intercultural Analysis of Differences in Appropriateness Ratings of Facial Expressions Between Japanese and American Subjects
}

Patricia Jean Peschka-Daskalos

Portland State University

Follow this and additional works at: https://pdxscholar.library.pdx.edu/open_access_etds

Part of the Speech and Rhetorical Studies Commons

Let us know how access to this document benefits you.

\section{Recommended Citation}

Peschka-Daskalos, Patricia Jean, "An Intercultural Analysis of Differences in Appropriateness Ratings of Facial Expressions Between Japanese and American Subjects" (1993). Dissertations and Theses. Paper 4700.

https://doi.org/10.15760/etd.6584

This Thesis is brought to you for free and open access. It has been accepted for inclusion in Dissertations and Theses by an authorized administrator of PDXScholar. Please contact us if we can make this document more accessible: pdxscholar@pdx.edu. 
AN ABSTRACT OF THE THESIS OF Patricia Jean Peschka-Daskalos for the Master of Science in Speech Communication presented April 28, 1993.

Title: An Intercultural Analysis of Differences in Appropriateness Ratings of Facial Expressions Between Japanese and American Subjects

\section{APPROVED BY THE MEMBERS OF THE THESIS COMMITTEE:}

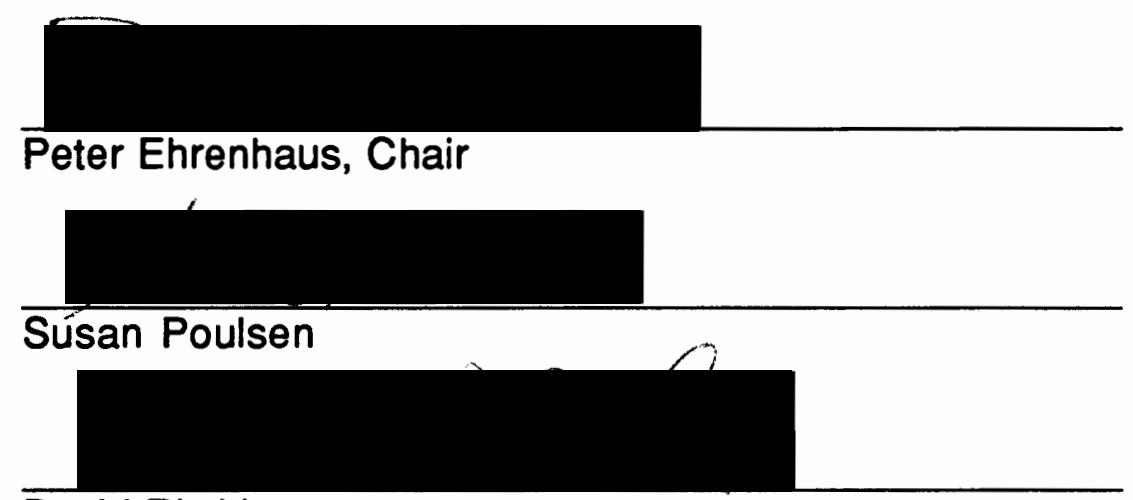

\section{David Ritchie}

In 1971 Paul Ekman posited his Neuro-Cultural Theory of Emotion which stated that expressions of emotion are universal but controlled by cultural display rules. This thesis tests the Neuro-Cultural Theory by having subjects from two cultures, Japan and the United States, judge the perceived appropriateness facial expressions in social situations. Preliminary procedures resulted in a set of scenarios in which socially 
appropriate responses were deemed to be either "Happy", "Angry" or "Surprised". Data in the experimental phase of the study were collected using a questionnaire format. Through the use of a 5-point Likert scale, each subject rated the appropriateness of happy, anger and surprise expressions in positive, negative and ambiguous social situations. Additionally, the subjects were asked to label each expression in each situation. The responses were analyzed statistically using Analysis of Variance procedures. Label percentages were also calculated for the second task in the study. No support was found for two of the three research hypotheses, and only partial support was found for a third research hypothesis. These results were discussed in terms of the need for greater theoretical and methodological refinements. 


\title{
AN INTERCULTURAL ANALYSIS OF DIFFERENCES IN APPROPRIATENESS RATINGS OF FACIAL EXPRESSIONS BETWEEN JAPANESE AND AMERICAN SUBJECTS
}

$$
\text { by }
$$

PATRICIA JEAN PESCHKA-DASKALOS

A thesis submitted in partial fulfillment of the requirements for the degree of

\author{
MASTER OF SCIENCE \\ in \\ SPEECH COMMUNICATION
}

\author{
Portland State University
}

1993 
TO THE OFFICE OF GRADUATE STUDIES:

The members of the Committee approve the thesis of Patricia Jean Peschka-Daskalos presented April 28, 1993.

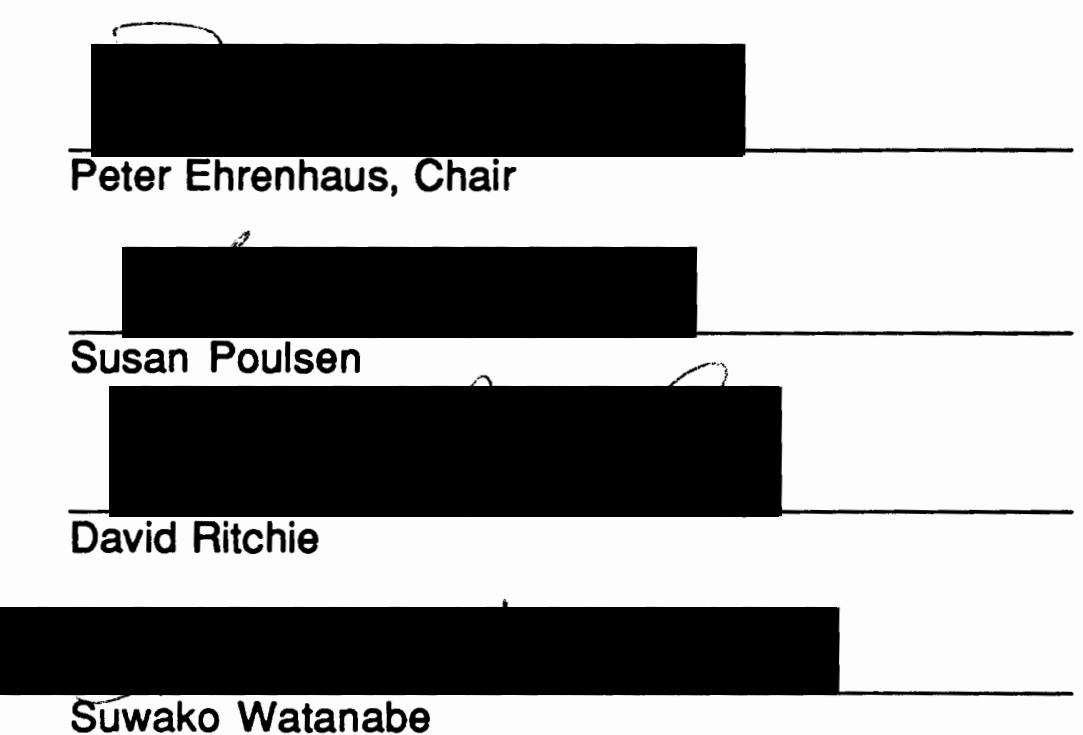

\section{APPROVED:}
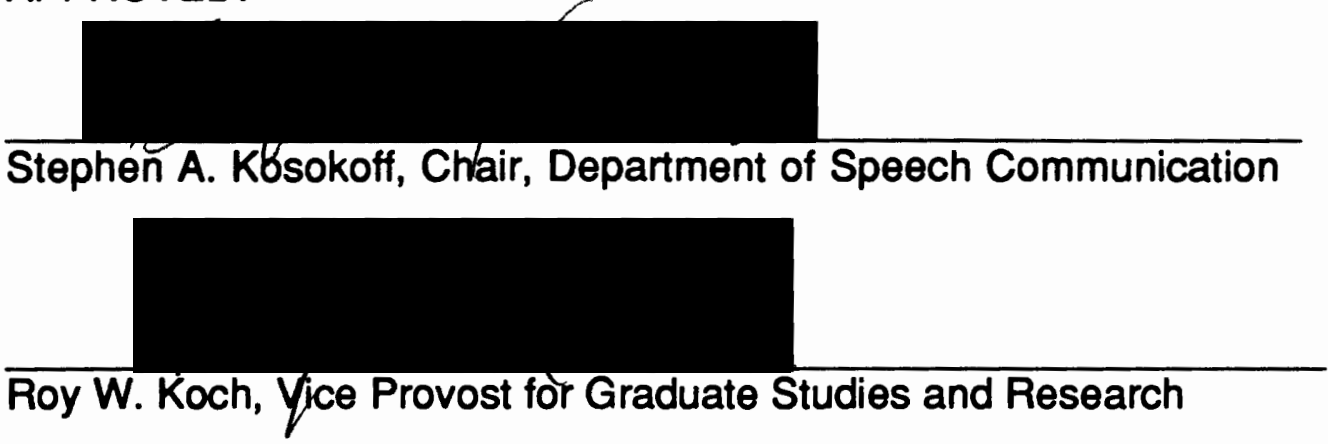


\section{ACKNOWLEDGEMENTS}

The completion of my Masters degree has taken a course of about 5 years. It would have taken a millennium without some special help from some special people.

Almost everyone in my life has made a comment about my Masters degree, and have consequently had an influence on its course of development. But, five key people have been the driving force behind its completion.

Dr. Peter Ehrenhaus, my thesis chairperson, is one of the five. Peter certainly kept me on track, using his "hammer of knowledge" to help me produce a document that I am very proud of. Thank you Peter for your direction, suggestions, praise and support. You are an excellent Mentor.

Mom and Dad had a great deal to do with my accomplishments. They taught me the importance of excellence, and always praised a job well done. Plus, somehow my tuition got paid every term (and thanks for paying the late fees too!). Thank you for your help, support and belief in my abilities. I love you both.

Paul, my husband, is another reason I finally finished my degree. Paul had more confidence in me, than I had in myself. He knew better than I, that I could do it. Thank you for listening to and reading endless pages about expression appropriateness (especially in the middle of Trailblazer games, Braves games, and Raider games). Thank you for believing in me. I love you. 
The final influence is Baby Daskalos. Although you're not here yet, you are a major reason why I finished my degree. I love you. Thank you for the inspiration!

Five years has certainly been a long time. To all others not mentioned here who help me along the way, Thank you. 


\section{TABLE OF CONTENTS}

ACKNOWLEDGEMENTS $\ldots \ldots \ldots \ldots \ldots \ldots \ldots \ldots \ldots$ iii

LIST OF TABLES $\ldots \ldots \ldots \ldots \ldots \ldots \ldots \ldots \ldots \ldots \ldots \ldots \ldots$ viii

LIST OF FIGURES $\ldots \ldots \ldots \ldots \ldots \ldots \ldots \ldots \ldots \ldots \ldots \ldots \ldots$

CHAPTER PAGE
PH

I INTRODUCTION ..................... 1

Facial Expression of Emotion Research

History ................. 3

II REVIEW OF LITERATURE $\ldots \ldots \ldots \ldots \ldots \ldots \ldots \ldots$

Theoretical Background ............ 7

Cultural Relativity ............ 8

Universality................. 16

Neuro-Cultural Theory............ 24

Display Rule Research . . . . . . . . . 29

Cultural Differences .................. 36

Purpose .................... 38

Key Concepts . . . . . . . . . . . . . . 38

Hypotheses and Research Question ..... . 39

III METHODOLOGY ....................... 42

The Sample .................. 42

Japanese Population Characteristics . 43 American Population Characteristics . . 44 
Instrument and Method ............. 44

Instrument--Phase I........... 45

Procedure--Phase $1 \ldots \ldots \ldots \ldots \ldots, 46$

Phase I Results ............... 47

Instrument--Phase II ........... 48

Procedure--Phase II............ 51

IV DATARESULTS ..................... 54

Hypotheses Testing ............... 54

Hypothesis 1 Test . . . . . . . . . . . . 55

Hypothesis 2 Test . . . . . . . . . . 58

Hypothesis 3 Test ............. 62

Research Question ................6 63

V DISCUSSION ..................... 67

General Analysis of Evidence ......... 67

Discussion of Hypotheses . . . . . . . . . . 68

Hypotheses 1 and $3 \ldots \ldots \ldots \ldots \ldots 68$

Hypothesis $2 \ldots \ldots \ldots \ldots \ldots \ldots \ldots .71$

Discussion of Research Question ........ 74

Post-Inteniews . . . . . . . . . . . . 75

Limitations ................. 76

Future Directions ............... 77

REFERENCES $\ldots \ldots \ldots \ldots \ldots \ldots \ldots \ldots \ldots \ldots \ldots \ldots \ldots \ldots \ldots \ldots \ldots$

APPENDICES

A PHASEIQUESTIONNAIRES ............. 83

B PHASE II QUESTIONNAIRES FOR AMERICAN

SUBJECTS ................. 86 
C PHASE II QUESTIONNAIRE FOR JAPANESE

SUBJECTS $\ldots \ldots \ldots \ldots \ldots \ldots \ldots \ldots, 91$

D CAUCASIAN FACIAL EXPRESSION

PHOTOGRAPHS................. 96

E JAPANESE FACIAL EXPRESSION

PHOTOGRAPHS ................. 100 


\section{LIST OF TABLES}

\section{TABLE}

I Percentage Rates of Recognition of Six Affects Among a

Sample from the United States, Brazil, Japan,

New Guinea and Borneo . . . . . . . . . . . . . . . . . . 22

II Versions of Questionnaires by Expression and Situation . . 49

III Sample Size by Questionnaire Version within Each Culture . 50

IV ANOVA Results of Ambiguous Situation (Hypothesis 1). . . 55

V Appropriateness Rating Group Means by Expression and

Situation for Japanese and American Subjects. . . . . 57

VI Follow-Up Scheffe Pair-Wise Comparison Results in

Ambiguous Situation for Japanese and American

Subjects $\ldots \ldots \ldots \ldots \ldots \ldots \ldots \ldots \ldots \ldots \ldots \ldots$

VII ANOVA Results of Positive Situation (Hypothesis 2). . . . . 59

VIII Follow-Up Scheffe Pair-Wise Comparison Results in

Positive Situation for Japanese and American

Subjects $\ldots \ldots \ldots \ldots \ldots \ldots \ldots \ldots \ldots \ldots \ldots 60$

IX ANOVA Results of Negative Situation (Hypothesis 3) ..... 62

$X \quad$ Expression Label Response Percentages for Japanese

and American Subjects for each Pairing of

Expression and Situation .................... 64 


\section{LIST OF FIGURES}

1. Eyebrow, Eye, and Mouth Types used by Cuceloglu to Generate a Matrix of Facial Expressions . . . . . . . 15

2. Illustration of How Display Rules Affect Emotional Facial Patterns ............................ 25

3. Scheffe Formula Used to Compute Follow-Up Pair-Wise Expression Differences

4. Significant Interaction Effect of Japanese and American Appropriateness Ratings in Positive Situation . . . . . 61 


\section{CHAPTER I}

\section{INTRODUCTION}

The study of intercultural communication is of growing concern. The world is experiencing an inevitable increase in intercultural communication because of global political and economic interdependence. "Understanding and heeding cultural variables...is critical to success in international business" ("Understand and Heed," 1990, p. 26). "A number of firms are learning the hard way that successful domestic strategies do not necessarily work overseas and that businesses must be adapted to other cultures" ("Understand and Heed," 1990, p. 27).

Adaptation to culture requires an awareness of the differences that exist. This study seeks to examine cultural differences between members of the dominant American culture and the members of one country in the Pacific Rim, Japan. Research will focus on the the recognition and identification in modes of emotion expression.

The United States is Japan's leading export and import trade partner ("Snapshot," 1991). Japan is the United States' second leading foreign market for exports and imports ("US Trade," 1990). Therefore economic importance of Japan to the U.S. and visa versa is obvious. However, establishing and maintaining that trade relationship is not easy. Companies that try to launch services and products in Japan find the going rough. For Instance, Compaq Computer Corporation blames the rocky road on cultural 
gaps (Higgins, 1991). Clifford Clark, intercultural consultant, has found some 100 cultural differences between United States and Japanese standards (Galagan, 1990). Some of these differences are based on communication styles and values (Galagan, 1990). Clark has stated that "everything we think is culture free or universal is not. That's why the need to develop global awareness never stops" (Galagan, 1990).

In light of Japan's economic importance, it has become popular to attempt to develop awareness and help establish or maintain relationships with Japan through intercultural investigation. Cities in the United States and Japan "adopt" each other as sister cities so information can be shared. Exchange students spend time in each other's countries to learn first hand about each other's cultures. Intercultural research is undertaken to acquire new information and to expand and refine on what is already known.

This study endeavors to add to the existing intercultural knowledge base. Earlier studies have addressed intercultural communication. However of specific importance to this thesis is past work conducted concerning Japanese and American differences in emotion expression. This previous research has shown Japanese and American subjects differ in expression of emotion (Ekman, 1971; Friesen, 1972) and perception of emotion (Ekman et al., 1987; Matsumoto, in press; Matsumoto \& Ekman, 1989). This thesis will expand on the issue of emotion expression and focus specifically on Japanese and American differences in the perceived appropriateness of facial expressions.

If differences exist, it is possible they are controlled by display rules (Ekman, 1971). Display rules are defined as cultural habits or standards 
that control facial behavior. According to Burgoon, Buller \& Woodall (1989) a culture formulates display rules that indicate when, how and with what consequences expressions will be exhibited. Therefore, even innate facial expressions may appear with different frequencies, many possible interpretations, and with a varying degree of social approval across cultures. This means even though the expression may be considered universal (constant across all cultures), it is still difficult to make pan-cultural generalizations about expressions. To avoid making these generalizations it becomes necessary to determine if display rules exist, if they vary from culture to culture, and if so, in what situations.

\section{FACIAL EXPRESSION OF EMOTION RESEARCH HISTORY}

Facial expressions of emotion have been studied since the late 1800 's. Charles Darwin was the first to address emotion expression in his 1872 book, The Expression of Emotion in Man and Animals. As early as 1924 other researchers began publishing texts and articles concerning emotion expression (Allport, 1924; Asche, 1952; Birdwhistell, 1963, 1970; Boucher \& Carlson, 1980; Cuceloglu, 1970; Dickey \& Knower, 1941, EiblEibesfeldt, 1970, 1972; Ekman, 1971; Ekman \& Friesen, 1971; Ekman \& Friesen, 1986; Ekman et al., 1987; Ekman, Sorenson, \& Friesen, 1969; Friesen, 1972; Izard, 1971; Klineberg, 1938; Labarre, 1947; Leach, 1972; Matsumoto, 1990, 1991, in press; Matsumoto \& Ekman, 1989; Matsumoto \& Hearn, 1991; Motely \& Camden, 1988; Tomkins, 1962; Triandis \& Lambert, 1958; Vinacke, 1949; Vinacke \& Fong, 1955). Specific lines of inquiry have centered upon the labelling of expressions, facial action coding (FACS), 
cultural differences in emotion expression, display rules, universality of emotions, consequences of emotion expressions, and facial gestures. Although there are several aspects of expression of emotion, this project will focus on cultural differences regarding perceived appropriateness of facial expression in Japanese and American cultures. Perceived appropriateness is most likely controlled by display rules.

The idea of cultural differences in display rules is well accepted, although there has only been one cross-cultural study (Friesen, 1972) that has documented their existence. Matsumoto, Wallbott and Sherer (1989) admitted that since the original display rule study by Friesen was conducted in 1972, few studies have tested the boundaries and limits of the display rule concept. No studies have investigated how display rules differ for different types of emotion. Matsumoto (1991) also suggests the need for further research which explores discrepancies between display rules and actual displays.

Whether or not culture affects emotion expression is a question that remains unanswered. Since 1872, a great deal of research has been conducted on cultural differences in the expression of emotion. Two alternative views regarding intercultural differences in expression of emotion have arisen. Some researchers believe that expressions of emotion are culture specific (controlled by cultural boundaries). Others argue expressions of emotion are universal. The universal point of view has most recently been the predominant view. In 1971, Paul Ekman posited his Neuro-Cultural Theory. This theory is essentially a compromise of the 
universal and cultural relativity theories. It suggests that facial expressions are universal, but controlled by cultural display rules.

More recently, Matsumoto (1990) and Matsumoto \& Hearn (1991) produced evidence that display rules do exist. In both of their studies, they investigated cultural differences in display rules by asking subjects in different cultures to report on the appropriateness of expressions in various situations. However, their situation descriptions provided the subjects with only relationship cues. The descriptions provided no contextual definitions. Ekman's (1971) display rule theory suggests there are four characteristics which are taken into account when a display rule is used. Those characteristics are: 1) static personal characteristics (e.g., age, sex, and body size); 2) transient personal characteristics (e.g., roles, attitudes); 3) static social characteristics (e.g., social definition of a situation, such as funeral, job interview); 4) transient interaction characteristics (e.g., exits, listening, talking, entrances). Matsumoto (1990) and Matsumoto \& Hearn (1991) supply only characteristics 1 and 2 to the subjects in their studies. Therefore, the research completed to date has not fully tested the display rule theory. Consequently, many questions regarding cultural differences in emotion expression remain unanswered.

It is important to ask whether Matsumoto (1990) and Matsumoto \& Hearn (1991) would have found evidence confirming the existence of display rules if their situation descriptions had contained all four characteristics described by Ekman. Cultural emotion expression research that uses Ekman's four characteristics may not only shed light on the display 
rule issue, it may also provide evidence suggesting that decoding or labelling expressions is a different process than interpreting expressions.

Ekman et al. (1987) provided evidence that six cultures could accurately label or decode six "universal" expressions. The six "universal" expressions named by Ekman, et al. (1987) are: "Happy", "Angry", "Sad", "Surprise", "Fear", and "Disgust". The subjects in his study matched expression labels to photographs of expressions. The researchers however, did not address the interpretation of expressions.

The purpose of this thesis is to use the four characteristics of display rules suggested by Ekman (1971), to incorporate them into situation descriptions and to have subjects from two distinct cultural groups assess the stimulus materials for the appropriateness of the facial expression. Adding the context descriptions will enable this researcher to examine cultural differences in interpreting emotion expressions. The results may provide evidence to substantiate the existence of display rules.

In the next chapter I shall review past literature relevant to the development of the concept of display rules. Also, I will also discuss the weaknesses of those studies and explain how those weaknesses shaped the methodology of this study.

Chapter III focuses specifically on the methods used to gather data. The fourth chapter contains data results and analysis. The final chapter discusses the meanings of the results, the support found for the research hypotheses, the limitations of this research, and suggestions for future research directions. 


\section{CHAPTER \|}

\section{REVIEW OF LITERATURE}

This chapter reviews the literature regarding the study of facial expression. Scholarly analysis completed since the late 1800 's can be organized into three groups. The first of these groups assumes emotions are culture bound, or relative to each culture. This group of researchers are know as cultural relativists. The second group assumes emotional expressions are universal or pan-cultural. These researchers are labelled as universalists. The third group, characterized by Ekman's Neuro-Cultural Theory, attempts to reconcile the differences in previous research noted by Ekman.

\section{THEORETICAL BACKGROUND}

In 1872 when Charles Darwin posited that human emotions are universal, he became the catalyst in a lengthy dispute regarding whether human emotion expression is innate or learned. Two schools of thought developed. The cultural relativists believed that emotions were learned and would therefore vary from culture to culture. Universalist argued that human expressions of emotion are pan-cultural, innate and constant across all cultures. 


\section{Cultural Relativity}

Four investigators (Klineberg, 1938; LaBarre, 1947; Birdwhistell, 1963, 1970; Leach,1972) posited theories of cultural relativity. The first research arguing the culture specific point of view was written by Klineberg in 1938. Klineberg reviewed several pieces of Chinese literature including: The Dream of the Red Chamber, and All Men are Brothers. The Dream of the Red Chamber was read in Chinese. He cited instances in the texts where Chinese expressions were different from expressions he would have expected in his native country. Although Klineberg noted some differences between cultures, the reliability, accuracy and generality are questionable because he accepted the informal report of a single observer, himself.

Weston LaBarre's 1947 writing cited examples of varying emotion expressions from numerous cultures. However, LaBarre's work concerned mostly body gestures rather than facial expressions. LaBarre discovered cultural differences in the meanings of raised eyebrows, winks and smiles. Later, Ekman (1973) labeled these movements as illustrators, regulators, and emblems, and not as emotion expression. Illustrators are defined as gestures that help explain a verbal message. Regulators are non-verbal gestures that control verbal language and emblems are replacements for verbal messages. LaBarre failed to distinguish facial gestures from facial expressions of emotion and was therefore examining a different phenomenon. Consequently, LaBarre offered no evidence of cultural relativity in emotion expression. There has been no dispute that gestures are culture-bound. 
Birdwhistell (1963) disagreed with Darwin's view of emotions being universal. His writings were mostly concerned with body movement, also known as kinesics. During his research he attempted to isolate a series of expressions and movements that would denote primary emotions. After several unsuccessful attempts, he concluded that these behavior characteristics were not universal, but were culture-bound. With his position that emotion symbols were not universal, he asserted:

to maintain some degree of predictability and order in social life, men within a given society must not only have comparable emotion experiences but must be able to share information about these experiences with their fellows. If such experiences and their expressions are not exclusively biological, we can expect them to be learned and patterned according to the particular structure of particular societies (p. 126).

Although this assertion seems reasonable, Birdwhistell provided no evidence to prove that emotions are not biological in origin; meaning they are learned.

Birdwhistell's 1970 text on kinesics includes a chapter examining the facial emotion of smiling. In his studies he noted frequency of smiles displayed in different regions of the United States. Unfortunately, he failed to define the situation in which the smiles occurred. He stated, "a smile in one society portrays friendliness, in another embarrassment, and, in still another may contain a warning that, unless tension is reduced, hostility and attack will follow" (p. 34). Birdwhistell compromised the accuracy and validity of his assertions because he did not report the situation in which the expressions were observed. It is impossible to determine if Birdwhistell 
observed the smile in identical situations across the country. If he observed the smile in various situations, he has no basis for claiming that his observations support the theory of cultural relativity. Birdwhistell is confident in his analysis, and stated that he determined through his research that "there were no universal...body motions, facial expressions, or gestures which provoked identical responses the world over" (p. 34). Birdwhistell offered no empirical evidence in either study to support the theory of cultural relativity.

Anthropologist Edmund Leach (1972) studied the relationship between nonverbal communication and cultural context. Leach asserted that individual human actions and gestures, whether conscious or unconscious, are capable of conveying information. His concern was not with the entire range of signals, but with the ones that are patterned in accordance with cultural convention. He contended that the meanings of symbols are highly dependent on contact and that people with different cultural expectations will form different opinions or conclusions from the same situations. Leach asserted an analogy between linguistic theory and nonverbal communication which concluded that any particular facial gesture will not have uniform cross-cultural significance. During his discussion of nonverbal communication, he drew conclusions that support cultural relativity, but he offered no quantitative evidence. Leach's conclusions are drawn only from an analysis of varying cultures' rituals, ( e.g., weddings or funerals).

A number of scholars have conducted research in an attempt to validate their theory of cultural relativity. Although all previously mentioned 
studies found similarities and differences, only one study claimed to have significantly validated the theory.

Dickey and Knower's (1941) study of American and Mexican children asked subjects to identify eleven simulated emotions. Each group responded to questionnaires written in their native languages. The subjects responded in small groups of eight to twelve. Dickey and Knower analyzed their data by looking for differences in the answers. When the data were analyzed they discovered that "all critical ratios except for...laughter indicated significant differences" (p. 191). The authors asserted that the most reasonable answer for these differences is a reflection of culture. Dickey and Knower failed to complete two procedures that would have strengthened their assertion of cultural relativity. First, there was no coding of the photographs. Since accuracy in labelling emotion expressions was the main issue in this study, the photographs should have been coded to ensure that the photos contained only "pure emotion", and were indeed reliable photos of the emotion intended. Untested photos may have depicted "blended emotions" or an emotion that was labelled incorrectly, which would call into question the reliability and validity of the research. There was also no back-translation of the emotion terms to ensure that the terms were as similar as possible for both cultures. In addition, only two different people's photographs were used in this study. According to Ekman (1973), when using only one or two people's photographs as stimulus material, the data is compromised for several reasons. The models in the photographs may be expressing emotions subconsciously affected by their cultural display rules. They may have unintentionally displayed blended 
emotions, or they may have physical quirks which limited their ability to display facial expressions. The results of this study are also limited because use of U.S. and Mexican subjects created a lack of visual isolation (Ekman, Friesen, \& Ellsworth, 1982). Visual isolation refers to a population having limited exposure to mass media and other cultures.

Seventeen years later, Triandis and Lambert (1958) compared urban Greek students, rural (village) Greeks and Urban U.S. students in their judgements of facial emotions. They asked students to place pictures of an emotion display into one of Schlosberg's (cited in Triandis \& Lambert, 1958) categories labelled "sleep-tension", "acceptance-rejection", or "pleasantunpleasant". Schlosberg (cited in Triandis and Lambert, 1958) reported that these categories are the "dimensions" required for subjects to judge pictures of emotion states. Each picture within a category was arrayed from least to greatest intensity. The results indicated the college students (U.S. and Greek) were more similar to each other than either student group was to the rural villagers. Triandis and Lambert attributed this to the college students having been exposed to the same stereotyped emotion expressions. The differences noted between the students and the villagers related to the "pleasant-unpleasant" category. The Greeks rated unpleasant pictures more toward tension and attention. The U.S. students rated the pictures just the opposite, pleasant toward tension and attention. Triandis and Lambert admitted this difference was very difficult to explain. Ekman (1973) suggested it may be a reflection of emotion--attitude differences. Overall, the study showed a low correlation. Triandis and Lambert were unable to validate the culture-specific theory. They stated, "there is little doubt that 
Greek subjects, even when they come from very different populations, rate emotion expressions in the same way as American subjects" (p. 23). The weakness of this study is its use of only one person's face in the photographs. As discussed earlier, using only one person's photograph as stimulus material jeopardizes the validity of the research. The person in the stimulus photos may be unintentionally displaying blended emotions, may have unknowingly displayed expressions controlled by display rules or may have physical limitations which affects their ability to display emotions. There was also a lack of visual isolation.

Vinacke (1949) also attempted to validate the cultural relativist theory of emotion expression. He expected to find differences in labelling among Hawaiian subjects. The subjects were divided into three groups: Caucasian, Japanese and Chinese observers. Each group identified spontaneous Caucasian facial emotion expressions chosen from magazines. He found "Japanese, Chinese, and Caucasians in Hawaii all displayed the same general pattern of interpreting the facial expressions of Caucasians. There are no qualitative differences, the three groups agreeing, in general, on the same emotion..."(p. 427). He also found that females agreed more often on emotions than did males. Vinacke attributed the lack of differences to the subject's similar national and racial ancestry. He offered no explanation of the females higher level of agreement.

Vinacke realized that one of the possible limitations of his study was that he only used stimulus pictures from the Caucasian race. In 1955, Vinacke and Fong completed part II of Vinacke's study and had Japanese, Chinese and Caucasian students label Oriental faces. They found that 
Japanese and Chinese showed more of an agreement on the expression label than did the Caucasians. This result validated one of the hypotheses that Orientals could more accurately identify Oriental faces than could Caucasians. In the two different studies, Vinacke found weak evidence to support cultural relativity, but admitted that the differences were so slight that no significant differences exist. Vinacke and Fong's explanation for this finding was that all of the groups live in Hawaii, therefore they were knowledgeable about the varying subcultures within their environment.

One of the more recent attempts to prove cultural relativity was completed by Cuceloglu in 1970. Cuceloglu asked college students in the United States, Japan, and Turkey to rate the applicability of forty emotion expressions labels to sixty (60) line drawings of the face. The line drawings consisted of combinations of four eyebrow types, three eye types, and five mouth types (see Figure 1). He reported some expressions were interpreted the same across cultures, while others were interpreted differently.

Cuceloglu concluded that it was possible that a coding system for facial expression exists across cultures, although it is not absolute. By Cuceloglu using the facial line drawings, he may have bypassed some of the problems associated with using a person's facial expression. However, this coding system has created other problems that must be addressed. These line drawings may have created facial expressions that do not exist and may omit expressions that do. Ekman (1973) stated that Cuceloglu's 60 line drawings included only a small proportion of what a face can actually show. Ekman also contended Cuceloglu created line drawings that were anatomically impossible for a human to display. One of the last problems 
cited by Ekman was that these line drawings could have also depicted blended, rather than pure emotion expressions.
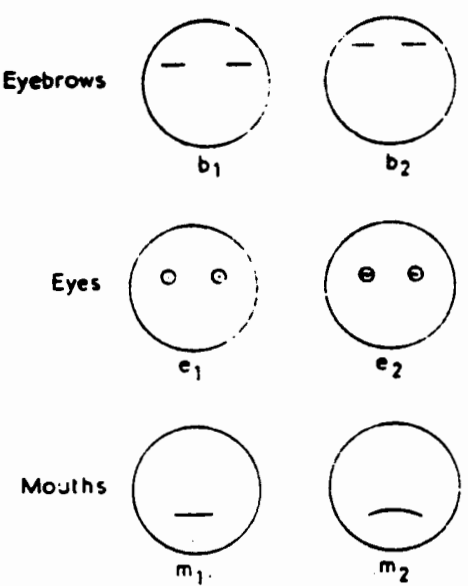
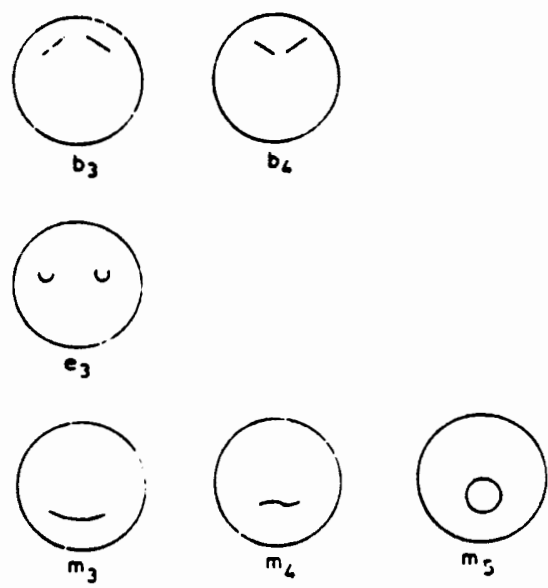

Figure 1. Eyebrow, eye, and mouth types used by Cuceloglu to generate a matrix of facial expressions.

In their attempts to prove cultural specific emotion expression, all but one researcher reported little success. Dickey and Knower (1941) did provide partial support for the theory of cultural relativity. However, these findings have never been replicated. Although the other researchers noted similarities and differences in their data, there were no significant differences reported.

Each of the studies investigating cultural relativity of expressions had methodological weaknesses. The most common weakness among these studies was the stimulus pictures. In all studies, only one or two stimulus person's photographs were shown to the research subjects. The stimulus emotion photos were never coded for reliability. And the stimulus emotions depicted in the line drawings were not anatomically possible. Ekman (1973) 
also points out none of the researchers controlled for visual isolation, and therefore limited the validity of their studies.

With the weaknesses of these studies in mind, it is important to consider the following: This author suggests that for the evidence to be most damaging to the universal theory, the data must have shown an emotion expression identified differently by subjects of two distinct cultures. For example, a happy expression would have to be labelled as contempt, or anger as sadness, or fear as happy, or surprise as disgust. Or, the data must have shown different cultures responded to identical emotional situations with different expressions. This type of evidence would have unequivocally validated the cultural relativity theory. To date, this evidence has not been provided.

\section{Universality}

While the relativists were attempting to prove the culture specific theory, the universalists (Darwin, 1872; Allport, 1924; Asch, 1952; Tomkins, 1962; Eibl-Eibesfeldt, 1970, 1972) were also exploring the physiological basis of universality. Darwin (1872) was the first to assert universality of facial expressions. His cross-cultural research contained methodological problems. Darwin asked people in other countries to respond to a sixteen question survey. There were two major problems with Darwin's research. First, Darwin relied on one subject's perception of the incident reported. The subject who completed the survey observed an incident in progress then answered the questionnaire. As discussed earlier, this limits the accuracy of the responses. Second, Darwin asked leading questions. Darwin 
described to the subject completing the survey what an emotion looked like and asked them if that is what they saw. For example, one of Darwin's questions was "Is astonishment expressed by the eyes and mouth being opened wide, and by the eyebrows being raised"? This type of question would evoke a biased response. An answer may be given to a question because a person knew what he or she might see. Darwin himself stated "the observer must be blind to the hypothesis, for if he knew what facial expressions were expected, he may imagine it" (p. 12). Consequently, under his own conditions, Darwin has damaged the reliability of his research and the validity of his findings.

Although Allport (1924) agreed with Darwin's theory of universal facial expressions, he reinterpreted it slightly. He believed that Darwin neglected the possibility that facial movement became an important factor in adaptation to a social environment. Therefore, Allport accepted Darwin's universal and innate principle "...With the important modification that the original serviceable reflexes, but not their expressive significance, are inherited" (p. 215). Allport offered no direct empirical evidence to support his claims (Ekman, Friesen, \& Ellsworth, 1982).

Solomon Asch (1952) also agreed with portions of Darwin's theory of universal facial expressions. Asch examined the evidence provided by earlier researchers and drew conclusions that supported the universalist perspective, but also allowed for cultural variations. Asch provided no new evidence of his own, but nevertheless contended that "certain expressions occur universally in response to a particular emotion experience" (p. 203). He left the door open however and continued, "there is also a wide area of 
expression that is culturally determined" (p. 203). Asch admitted the evidence to date is fragmentary. And, for the most part, he based his general conclusions from evidence facial gestures and expression elicitors information.

Tomkins (1962) was no more absolute in his convictions of universality than was Asch. The main concern of Tomkin's theory is primary affect. He developed a complex theory of facial affect. Tomkins asserted that primary affects are innate, but he also discussed the variables that could have been the cause of learned differences in expressions. He stressed universals, and wrote of "innate affect patterns". But he also stated that perception and interpretation of affect in facial expression is a skill that is culture bound. "The individual who moves from one class to another, or from one society to another is faced with the challenge of learning new 'dialects' of facial language to supplement his knowledge of the more universal grammar of emotion" (p. 216). He also wrote that miniaturized expressions, such as in overt expression of affect by the English can not often be detected by the Italian. However, other English would have no difficulty recognizing and interpreting the expression. Like Allport before him, Tomkins offered no empirical support for his theory.

In 1967 Eibl-Eibesfeldt started a study of cross-cultural human expressive behavior (1970). By videotaping people in various cultures (Europeans, Balinese, Papuans, Samoan, South American Indians) he found many detailed similarities between different cultures. He stated the similarities included such basic expressions as smiling, laughing, crying, and anger displays, but only offered video-taped evidence of cross-cultural 
similarities in raised eyebrows, embracing, kissing, or hiding the face when embarrassed. Although the latter contains only body movements, he contended the lists could be continued with many facial expressions. He admitted that there are differences between cultures that must be considered, but claimed that cultural variations are visible when the available universal patterns are used in slightly different ways. This assertion is based in his observation that culturally different patterns that develop are ultimately the same in principle across all cultures. EiblEibesfeldt's study of blind-born children (1972) showed that these children laugh, smile, cry, show surprise and anger the same way sighted children do. This research helped Eibl-Eibesfeldt draw the conclusion that the chance of learned facial expressions is practically nil. Therefore, facial expressions must be innate.

The first universalists who attempted to validate their theory empirically (Ekman, Sorenson, \& Friesen, 1969; Ekman \& Friesen, 1971; Ekman, 1971; Izard, 1971) had more success than the cultural relativists. Izard (1971) used posed photographs of American college students in his attempt to prove universality. Fifty male American college students gave free response descriptions for the photos. Following the free response, the photos were again projected to people in nine different cultures for classification into emotion categories. A dramatic $83 \%$ of the pictures were placed into the appropriate emotion category. That is, a majority of the people successfully matched photographic and verbal symbols of the emotions. Izard concluded that his findings suggest that emotions may be one of the most fundamental and universal phenomena in personality and 
culture. Ekman (1971) stated that the only weakness in Izard's study was a lack of visual isolation. There was also a significant inconsistency between the free response labelling accuracy and the accuracy of emotion category classification. When the fifty American males were asked to give free response labels to emotional affect displays of Americans, the average percentage of free responses that were judged to be in the intended emotion categories was only $62 \%$. Yet when the same pictures of the Americans were judged by people in nine different cultures, the average percentage of emotions judged into the intended categories increased by over $20 \%$, to $83 \%$. This discrepancy is never explained by the researchers. Other studies (Vinacke, 1949; Dickey \& Knower, 1941; Vinacke \& Fong, 1955) showed that subjects judging stimulus pictures within their own culture had a higher level of agreement than photos judged cross-culturally. The free-response procedure is less accurate because subjects are not given a list of emotion label choices from which to respond. However, because the free responses were collapsed into emotion categories instead of exact wording lists, some accuracy could be regained. The fact that Izard's findings contradict what Vinacke $(1949,1955)$ and other researchers concluded, question the reliability of Izard's conclusions.

One of the weaknesses of all the studies to date, according to Ekman, was their lack of visual isolation. Ekman, Sorenson, and Friesen (1969) controlled for this weakness by having subjects from pre-literate and literate cultures participate in their study. Subjects for the study were from the U.S., Brazil, Japan, New Guinea, and Borneo. The pre-literate cultures were the New Guinea subjects, who lived in cultural isolation until 12 years before the 
study. The second pre-literate group was from Borneo, which at the time of the study still maintained their traditional agrarian way of life. The researchers also controlled a second common methodological weakness by pre-testing the photographs used in the study.

The data that Ekman, Sorenson, and Friesen collected from the three literate cultures, as reported in Table I, indicate a majority of the subjects agreed on the labels of the expressions. The subjects in both the literate and preliterate cultures were able to accurately identify the happy expression. But the results of the pre-literate cultures showed significantly lower levels of agreement when all of the other expression categories were labelled. (See Table I)

The New Guinea and Borneo subjects showed an average of.less than $46 \%$ agreement rate for "Fear", "Disgust", and "Surprise". Borneo data contained the weakest results of the two pre-literate cultures. Forty percent $(40 \%)$ of the Borneo subjects labelled intended "Fear" photos accurately as "Fear", while another $30 \%$ labelled them as "Surprise". Of the "Surprise" photos, 36\% labelled them accurately, while $23 \%$ labelled them as "Fear". The weakest results were in the "Disgust" category. Twenty-six percent $(26 \%)$ of the Borneo's labelled the intended "Disgust" photos as "Sadness" and another $23 \%$ labelled them as "Happiness".

The New Guinea subjects performed slightly better. This group was divided into sub-groups consisting of subjects tested with Pidgen ${ }^{1}$ language

1 This group of New Guinea South Fore subjects performed the judgement task by using Pidgen translation of the affect terms. 
descriptions of emotion expression and a second group tested with Fore ${ }^{2}$ language descriptions of emotion expressions. The only noteworthy data beyond the general lack of accuracy when labelling expression was that among the Fore responses, $56 \%$ of the subjects labelled "Sadness" as "Anger".

\section{TABLE I}

\section{PERCENTAGE RATES OF RECOGNITION OF SIX AFFECTS AMONG A SAMPLE FROM THE UNITED STATES, BRAZIL, JAPAN, NEW GUINEA AND BORNEO}

\begin{tabular}{|c|c|c|c|c|c|c|}
\hline \multirow[b]{2}{*}{ Affect } & \multirow[b]{2}{*}{ US } & \multirow[b]{2}{*}{ Brazil } & \multicolumn{4}{|c|}{ New Guinea } \\
\hline & & & Japan & Pidgen & Fore & Borneo \\
\hline Happy-H & $97 \mathrm{H}$ & $97 \mathrm{H}$ & $87 \mathrm{H}$ & $99 \mathrm{H}$ & $82 \mathrm{H}$ & $92 \mathrm{H}$ \\
\hline \multirow[t]{2}{*}{ Fear $-F$} & $88 \mathrm{~F}$ & $77 \mathrm{~F}$ & $71 \mathrm{~F}$ & $46 F$ & $54 \mathrm{~F}$ & $40 \mathrm{~F}$ \\
\hline & & & $26 \mathrm{Sr}$ & $31 \mathrm{~A}$ & $25 \mathrm{~A}$ & $33 \mathrm{Sr}$ \\
\hline \multirow[t]{2}{*}{ Disgust-D } & $82 \mathrm{D}$ & $86 \mathrm{D}$ & $82 \mathrm{D}$ & $29 \mathrm{D}$ & $44 \mathrm{D}$ & $26 \mathrm{D}$ \\
\hline & & & & $23 \mathrm{~A}$ & $30 \mathrm{~A}$ & $23 \mathrm{H}$ \\
\hline \multirow[t]{2}{*}{ Anger - A } & $69 \mathrm{~A}$ & $82 \mathrm{~A}$ & $63 \mathrm{~A}$ & $56 \mathrm{~A}$ & $50 \mathrm{~A}$ & $64 \mathrm{~A}$ \\
\hline & $29 \mathrm{D}$ & & $14 \mathrm{D}$ & $22 F$ & $25 \mathrm{~F}$ & \\
\hline \multirow[t]{2}{*}{ Surprise-Sr } & $91 \mathrm{Sr}$ & $82 \mathrm{Sr}$ & $87 \mathrm{Sr}$ & $38 \mathrm{Sr}$ & $45 \mathrm{~F}$ & $36 \mathrm{Sr}$ \\
\hline & & & & $30 \mathrm{~F}$ & $19 \mathrm{~A}$ & $23 \mathrm{~F}$ \\
\hline \multirow[t]{2}{*}{ Sad-Sd } & $73 \mathrm{Sd}$ & $82 \mathrm{Sd}$ & $74 \mathrm{Sd}$ & $55 \mathrm{Sd}$ & $56 \mathrm{~A}$ & $52 \mathrm{Sd}$ \\
\hline & & & & $23 \mathrm{~A}$ & & \\
\hline
\end{tabular}

2 This group of New Guinea South Fore subjects performed the judgement task by using their own Fore language. 
Yet, with this evidence and these low agreement percentages, Ekman, Friesen and Sorenson claimed that their theory of pan-cultural facial expression had been, for the most part, supported in pre-literate cultures. They attributed the lower level of agreements to "enormous obstacles imposed by language barriers and task unfamiliarity" (p. 89). They pointed out "there were similar recognitions of "Happiness", "Anger" and "Fear" in all the samples and for "Disgust", "Surprise", and "Sadness" in two out of three samples. [They also maintained that] an affect category was never misidentified by the majority of observers in more than one of the pre-literate cultures sampled" (p. 89). The fact still remains that more than a majority of the New Guinea Fore subjects labelled "Sadness" as "Anger", and that $49 \%$ of the Borneo subjects labelled "Disgust" as either "Sadness" or "Happiness". Ekman had previously criticized other researchers for not obtaining visual isolation in their studies because the subjects in pre-literate cultures could help prove universality. Yet when he used pre-literate subjects, he claimed to have validated universality with questionable data. Ekman, Sorenson and Friesen believed they supported their pan-cultural theory in literate cultures. Upon close examination of the pre-literate data, it became apparent to this researcher, the pan cultural theory is yet to be unequivocally validated.

In 1971, Ekman and Friesen replicated their 1969 study with the New Guinea South Fore. The method of extracting affect labels was changed from the previous study. Instead of choosing written labels from a list, the subjects were shown three different pictures of three different facial affect displays and were simultaneously told a story. The subjects then picked the 
photograph of the emotion expression that corresponded with the story. With this method of questioning, Ekman and Friesen produced significant results. The South Fore subjects still had difficulty discriminating between "Fear" and "Surprise". The other emotions described had percentages showing accuracy and agreement up to $100 \%$. In the emotion categories (Happy, Sad, Anger, Fear, and Disgust) all except "Fear" had accuracy and agreement levels over 65\%. With these results, Ekman and Friesen provided empirical evidence to support the pan-cultural theory.

\section{Neuro-Cultural Theory}

Later that year, Ekman (1971) posited a theory which he called the Neuro-Cultural Theory of Emotion. Ekman was "struck" by the earlier findings that suggested universalists and cultural relativists may both be correct. The Theory is called Neuro-Cultural because it suggests there are two different sets of determinants of facial expression. "Neuro" refers to the innate facial affect patterning, which is the actual firing of neurons that create a particular facial pattern. "Cultural" refers to the other learned set of determinants: elicitors, display rules, and consequences. (See Figure 2).

An elicitor is the stimulus for a facial expression. Ekman contends that elicitors will vary across cultures. For example, at funerals Culture $X$ may show the sad face, while Culture $Y$ may show the broad smiling face. Therefore, the response to the stimulus "Funeral" varies according to culture.

Display rules are habits or standards that control facial appearance. They are learned management techniques and control the application of restrictions to emotion display under specified and varying circumstances. 
As depicted in Figure 2, display rules can intensify, de-emphasize, neutralize or mask facial affect programs.

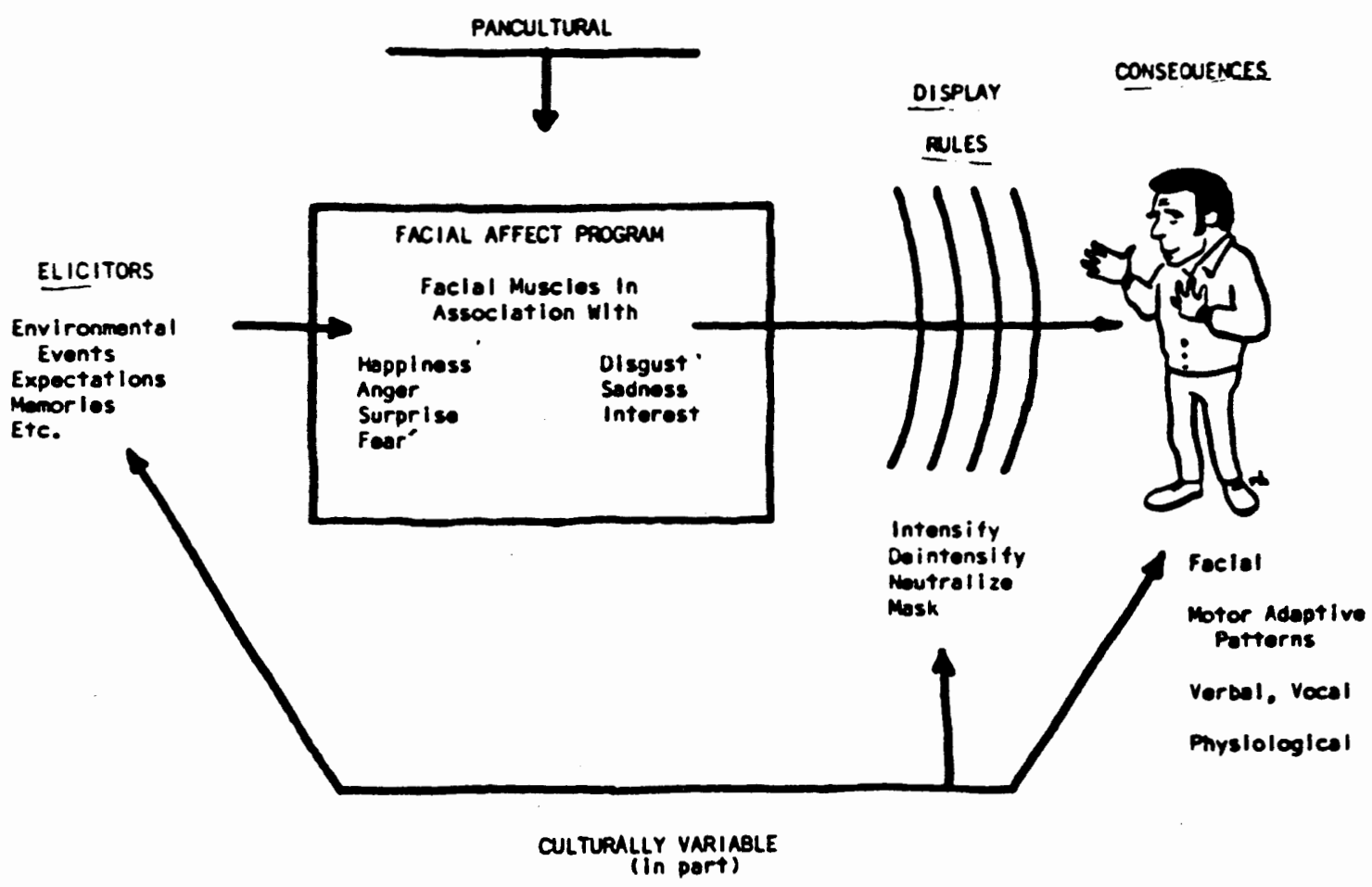

Figure 2. Illustration of how display rules affect emotional facial patterns. Copyright (C1972 by Paul Ekman. Used with permission.

As mentioned in Chapter I, Ekman contends that display rules may take four characteristics into account when specifying when and by whom a management technique is to be applied: 1) static personal characteristics (e.g., sex, age), 2) static social characteristics (e.g., social definition of situation such as funeral, job interview), 3) transient personal characteristics (e.g., role, attitudes), and 4) transient interaction regularities (e.g., listening, talking, out of play, in play). When display rules are operating, it is possible that in one culture the display rule calls for the management technique of 
intensifying sadness, while in a different culture, the display rules call for masking a sad expression with a pleasant one.

The current literature lacks verified specific ethnographic listings of noted cultural differences of affect displays, which could denote the possible existence of display rules. Earlier authors documented some cultural differences (Klineberg, 1938; LaBarre 1947; Eibl-Eibesfeldt, 1970). With the exception of Klineberg, the documented differences are primarily gestures, not facial expressions.

Klineberg (1938) noted some differences between his culture and various other cultures. He observed that the Japanese male will smile when he is scolded by his superior or will also smile at the announcement of the death of his son. Klineberg also reported the Chinese literature contains phrases describing culturally different facial expressions. For example, 'They stretched out their tongues' is not an act of defiance or a taunting action as it is in the United States. In China it is an expression of surprise. 'Her eyes grew round and opened' in the U.S. would signify fear or surprise, while in China it means anger.

LaBarre (1947) was primarily concerned with gestures, and he documented some gestural differences. He compared the gestures for 'yes' and 'no' in several different cultures. In the United States, 'yes' is signaled by an up and down motion of the head, while 'no' is signified by moving the head from left to right. Northern Ainu Japanese used "the right hand in negations, passing from right to left and back in front of the chest; and both hands are gracefully brought up to the chest and waved downwards--palms 
upward-- to signal affirmation" (p. 50). The Dyaks of Borneo raise their eyebrows to mean 'yes' and contract them slightly to mean 'no'.

Eibl-Eibesfeldt (1972) also noted differences in Greek and European culture, but again as with LaBarre, the differences documented are gestures, not facial expressions. "In Greece 'yes' is expressed as we [Europeans] do, but when saying 'no' the person jerks his head back, thus lifting the face. Often the eyes are closed and the brows lifted for a while" (p. 303).

In sum, there is a definite dearth of ethnographic information documenting cultural differences in facial expression. Therefore, ethnographic information cannot be relied upon to substantiate the existence of display rules.

As explained previously, the Neuro-Cultural Theory relies on three learned sets of determinants. The first set, "elicitors" has just been discussed. The concept of display rules is the second set of those determinants. Since there is a lack of ethnographic information to rely upon, quantitative research suggest display rules exist. Several articles provided evidence to validate the theory of display rules and attested to their existence (Friesen, 1972; Matsumoto, 1990; Matsumoto \& Ekman, 1989; Matsumoto \& Hearn, 1991). However, because this thesis relies heavily on validating the existence of display rules, these articles will be discussed later in this chapter.

The last aspects of facial expression characterized in Figure 2 are the consequences of emotion expression. Ekman (1971) claims there are six different consequences of emotion arousal. First is the facial behavior dictated by the facial affect program, which will occur uninhibited if there is 
no interference by display rules. The second consequence is the masking of facial behavior. The masking behavior is controlled by display rules to override and conceal the facial behavior originally dictated by the innate facial program. The third consequence is a secondary reactive feeling to the original feeling. When grandfather dies, a feeling of happiness because of an inheritance, may be followed by shame for feeling that way. This reactive consequence often makes is difficult to identify the primary elicited facial expression. Fourth is a motor adaptive pattern. This pattern could involve the body as well as the face. Examples would be biting the lip, a heavy sigh, or blowing out air. The fifth consequence is verbal behavior. This consists of words, possibly describing feelings or the act of giving messages to others. The final consequence is physiological change. Ekman contends physiological change is not observable.

Ekman asserts the most immediate behavioral consequences of emotion (masking, reactive, verbal/vocal, motor adaptive) are socially learned ways of coping with emotion. These consequences will vary within cultures as well as between. The physiological changes most likely are not as socially programmed, but are influenced somewhat by social learning. Although facial expressions are universal, they can be interfered with by display rules and by culturally variable events.

The most important aspect regarding elicitors, display rules and consequences of emotion arousal is that they show how and explain why researchers sometimes note cultural differences in emotion expressions. As Ekman reported, observation of different consequential emotion behavior following or coinciding with the same facial expression in two cultures 
should not be regarded as fact that the facial expression has two different meanings. It would actually support the theory that the two cultures have different ways of coping with a particular emotion in a particular setting. With the Neuro-Cultural Theory, both the innate/universal and learned/culturespecific findings concerning facial expressions are explained. The NeuroCultural Theory is the foundation on which this study is built.

\section{Display Rule Research}

Ekman's (1971) Neuro-Cultural Theory has been supported by Friesen, 1972; Matsumoto, 1990; Matsumoto \& Ekman, 1989; and Matsumoto \& Hearn, 1991. There has also be research completed that documents the existence of display rules (Friesen 1972; Matsumoto, 1990; Matsumoto \& Hearn, 1991). Friesen's (1972) study examined facial reactions of both Americans and Japanese when watching stress films. The Japanese masked their negative expressions with a smile when watching the film with a high status scientist from their own cultures viewed the film from the same room more than Americans did. This research did not study the display rules directly. Rather, it examined the operation of the rules through the actual behavior responses. Friesen accounted for these findings with the Neuro-Cultural Theory of emotion and concluded it was cultural display rules that caused the Japanese subjects to mask their negative feelings.

One weakness of Friesen's (1972) work was in regard to the external validity of this study. Friesen's (1972) research design did not allow him to conclude that display rules operate for all emotions. By studying the 
responses to negative emotions, the only acceptable conclusion that can be drawn is negative emotions appear to be controlled by display rules. Friesen cannot name the specific negative emotions because his operationalization did not allow for specifically defining which emotions were expressed. Therefore, display rule existence has been validated for only a non-specific category of negative emotions.

The primary interest of Matsumoto and Ekman's (1989) research was to measure cultural differences in intensity ratings of emotions by Japanese and American subjects. An additional outcome of their work was another validation of the existence of display rules. The Japanese subjects attributed less intense ratings of the emotion expressions they saw than did the Americans. Matsumoto \& Ekman reasoned that since display rules in Japan prohibit public display of negative emotions, these same rules might cause the Japanese to abate the extent of the emotion they see. Matsumoto and Ekman suggested that Japanese display rules could have controlled any undue expression of emotion, positive as well as negative, and influence the intensity levels that Japanese were willing to report . Matsumoto and Ekman used the display rule theory in an attempt to explain the results of their experiment. Their assertion that display rules controlled facial behavior did not provide data documenting display rule existence. As Matsumoto (1990) said, research is sorely needed to further our understanding of display rules.

Matsumoto and Hearn (1991) studied display rule differences between the United States, Poland, and Hungary. Display rules were operationalized as expression appropriateness. They conceptualized 
culture as being "shared beliefs, attitudes, and values communicated from generation to generation via language, observation or example" (Barnow, 1985 cited in Matsumoto \& Hearn, 1991, p. 3). They choose to measure cultural display rules with the cultural dimensions of individualism/ collectivism and power/distance. Through the use of these dimensions, Matsumoto and Hearn interpreted cultural differences in emotion and display rules in conjunction with the social distinctions labelled in-group, out-group, and status. In general, they predicted cultures high in individualism would rely less on in-groups and cultures high in collectivism would rely more on in-groups. These assumptions are based on the idea that individualistic cultures should produce greater variation in display rules than collective cultures because individualistic cultures place greater emphasis on individuality and freedom and therefore have less reliance on group conformity. Collective cultures should produce more agreement in display rules because of a greater degree of conformity required by their cultures. Matsumoto and Hearn also predicted fewer differences in reports of display rules for low power-distance cultures and a greater difference in display rules for high power-distance cultures.

To test these ideas, the subjects viewed universal facial expressions and rated the different situations for appropriateness on a nine point scale. The described social situations used in the study were relationship labels including: alone, close friends, family members, in public, casual acquaintances, people with higher status, and people with lower status. Scores for 'close friends' and 'family members' were averaged to produce in-group scores. Scores for 'in public' and 'casual acquaintances' were 
averaged to produce out-group scores. The other categories were analyzed individually. Two weeks after the first study, the subjects viewed a second set of photos and labelled the emotion and its intensity.

Matsumoto \& Hearn (1991) posed several hypotheses, the following of which were validated. The first hypothesis was that all subjects would rate emotions more appropriate with in-group others than with out-group others, but that the degree of difference would be larger for Americans than for Poles or Hungarians. The second hypothesis was that Americans would rate emotions more appropriate with lower-status others in comparison to higher-status others, but that the ratings for Poles and Hungarians would not differ according to status. The final hypothesis was that Americans would have higher absolute ratings than the Poles or Hungarians, regardless of emotion or situation. Matsumoto \& Hearn (1991) explained their results by reasoning that cultural differences occurred with the magnitude of the ingroup, out-group ratings because inter-group harmony fostered by collective cultures such as Poland and Hungary This inter-group harmony would produce smaller differences between in-groups and out-groups than individualistic cultures (United States) that do not foster the same degree of inter-group harmony. Cultural differences in display rules as a function of status were predicted on the the basis of cultural differences in power/distance. American culture is higher on power/distance than the Polish or Hungarian cultures. Therefore Americans modify their expressions to a larger extent on the basis of self-other status relationships. Communism down-plays status, thus Poles and Hungarians will not have learned to modify their emotion displays according to status. 
The authors of this article admitted there were limitations to their research. Sample representativeness is always an issue when subjects are students used from individual cities, and are required to participate to complete a course. Almost more importantly, the operationalization of display rules in this study was limited. Appropriateness is certainly an important issue, but as the authors of this article stated, their findings suggested that an evaluation of behavioral responses relative to appropriateness must be included. People within different cultures may agree that a certain expression is inappropriate, yet they may not agree on what would be the appropriate alternative. A study including behavioral responses could shed light on this issue. The additional limitations of this study noticed by this author will be addressed following Matsumoto (1990), as the major weaknesses of both studies are similar.

Matsumoto (1990) completed research examining the differences in display rules in Japan and The United States. He referenced the same theoretical framework of individualism/collectivism and power/distance as he did in his research with Hearn (1991) and based this research on the same theoretical assumptions. A very similar method was also used when gathering data, with the exception that Japanese and American subjects were used and they were additionally asked to rate how frequently they displayed each expression. Matsumoto tested eight hypotheses concerning cultural differences as a function of in-groups and out-groups. The results of the tests provided partial support for the following three hypotheses. The first hypothesis stated the Japanese would rate anger and fear to out-groups as more appropriate than would the Americans. The second hypothesis was 
that the Americans would rate disgust and sadness to in-groups as more appropriate than would the Japanese. The third hypothesis confirmed in part that the Japanese would rate anger as more appropriate to lower-status individuals than would Americans. Matsumoto discussed the reasons for his findings as follows. "Japanese rated anger to out-groups as more appropriate than Americans because Japanese culture fosters greater differentiation between in-groups and out-groups, which facilitates in-group harmony" (p. 210). To explain support of the second hypothesis, Matsumoto reasoned that Americans rated disgust and sadness to in-groups more appropriate than Japanese because the American culture is more accepting of negative emotions in in-groups. The negative emotions in American culture are not as threatening to cohesion or harmony because individualism is stressed over collectivism. Support of the third hypothesis was explained because in the Japanese society, more negative expressions are tolerated toward lower-status others in attempts to maintain the power distances within that type of society. Americans stress equality, and would not allow negative emotion displays to lower-status others.

Again, Matsumoto admitted there were limitations to his research. He suggested that the exact type of social differentiation is necessary in order to predict differences in emotion displays. He concluded display rules are most likely so strongly associated with contexts and situations that a definition of one without the other would be meaningless in cross-cultural contexts. He noted for a second time that the operationalization of display rules needs to incorporate the behavioral responses relative to 
appropriateness. It would be important for the subjects to report what they would show on their faces if they were in the situations described.

The studies completed by Matsumoto (1990) and Matsumoto \& Hearn (1991) have incomplete situation descriptions. Matsumoto realized context and situation are strongly associated with each other, but used only descriptions of relationships in his questionnaires. The situation description used in both studies left too much room for assumed variance. The description 'in public' could refer to playing frisbee in a park, or to studying in a library. A 'casual acquaintance' could be the person you sit next to in class, a co-worker, or your doctor. The situations needed to be described in detail. As Ekman's Neuro-Cultural Theory states, elicitors are important aspects of the total phenomena of facial display. Vividly and specifically described situations, could have helped control the possible variations in the subjects' responses to the different situations.

Earl Babbie (1992) provided an excellent explanation of why people have different definitions of the same situations. His point was that concepts such as "appropriateness" do not exist in reality. People make their terms real by assigning mental images and terms to the concepts. Providing detailed descriptions would help subjects define situations and help decrease variation. As Ekman (1971) suggested, it would also be important to include context and relational cues within a situation description. With strong situational definitions, meaningful cross-cultural data can be assimilated that will provide significant information regarding display rules.

Matsumoto also identified a second flaw in his research; he failed to have the subjects report how they would have behaved in the situations. 
This information could have helped to determine the actual consequences of emotion arousal. Again, Ekman (1971) discussed in the Neuro-Cultural Theory, the importance of examining the consequences of emotion arousal. What would be the behavior of person in a certain culture when their display rules are operating, and they are experiencing emotion arousal? The answer to this question will again provide significant data for cross-cultural comparison.

A third weakness of Matsumoto \& Hearn (1991) and Matsumoto (1990) that needs to be addressed briefly was the possibility of subject attrition. Because the second part of the research was conducted two weeks after Part 1, it was possible that not all of the same subjects participated in both parts of the study. This situation would not affect the data analyzed separately, but it must be mentioned when considering the data that were cross-analyzed with the data from the second test date. This thesis will modify the situation descriptions in Matsumoto's studies to eliminate the problem associated with a lack of contextual information.

\section{CULTURAL DIFFERENCES}

Differences in American and Japanese cultures suggest that differences in display rules should also exist. The specific cultural differences in display rules, the exact causes of those differences, and the consequences of display rules have yet to be determined. Matsumoto (1990) and Matsumoto \& Hearn (1991) contended those differences in display rules are caused by Japanese and American differences in cultural dimensions that Hofestede (cited in Matsumoto, 1990) labels as 
individualism/collectivism and power/distance. As discussed earlier, the limitation of the two former studies was in the absence of contextual situation description.

Display rules may be influenced by the Japanese society's greater degree of emphasis on values placed upon collectivisim. In Japan, emphasis on collective social groupings gives priority to the rights to the groups more than to the participating individual members (Haglund, 1988). As children are raised in Japan, incisive pressure is exerted on the child primarily to consider duties to others. The child is directed to believe that their own will should be considered secondary to that of others (Haglund, 1988). From childhood, Japanese are taught the importance of collectivity and are oriented to subordinate themselves to the group "One must follow form and do the expected. One must not stand out" (Condon \& Yousef, p. 238). Deru kugi wa utareru translated means "the nail that sticks up is hit". This phrase reminds Japanese of the pain experienced when one fails to blend harmoniously into a group (Cathcart \& Cathcart, 1988). It is possible, the greater extent of cultural pressure to conform may be the cause of Japanese following display rules. The opposite individualistic culture (The United States) does not as intensely pressure its citizens to conform. However, there still seems to be unwritten display rules that people conform to (e.g.,. big boys don't cry).

Individuals with power or status may influence the use of display rules (Friesen, 1972; Matsumoto, 1990; Matsumoto \& Hearn, 1991). Friesen's (1972) research shows the Japanese subjects tend to conform to those display rules more than the Americans. This could be explained by the 
Japanese culture placing more value in age or experience or high status others (Condon \& Yousef, 1975). The greater extent of social importance of conforming to display rules may also explain the behavior of saving face, which is of consequence in Japan (Argyle, 1988). This information about cultural differences provides a basis for predicting there may be differences between the United States and Japan regarding the existence of display and different levels of appropriateness of facial expressions in certain situations.

\section{PURPOSE}

The purpose of this thesis is to test Ekman's Neuro-Cultural Theory by comparing the appropriateness of the universal facial expressions of emotions in varying, but specific situations by Japanese and U.S. respondents. The various situations presented to the research subjects will be common to both cultural groups, as they were generated by subjects from Japan and the United States.

\section{KEY CONCEPTS}

The following concepts used within this study are defined as follows to assist in greater understanding of the research.

Display rules: Cultural rules or standards that control the expression of emotion and therefore help define the acceptability of facial behavior.

Appropriateness: A measure of the acceptability of an expression when cultural rules are considered.

Elicitor: The stimulus that creates an emotional facial expression. 
Context Cues: The cues or elicitors within a situation that describe the social definition of a situation, (e.g. funeral, job, class) and the interaction taking place within the situation (e.g. listening, observer, talking).

Relationship Cues: The cues or elicitors within a situation that describe the characteristics of people within a situation, (e.g. age, sex) and also the roles of people within the situation description, (e.g. friend, parent, teacher).

Ambiguous Social Situation: Social occurrence description including relationship and context cues generated through the use of a "Surprise" emotion expression photograph. "Surprise" is deemed ambiguous because previous research subjects had difficulty labelling the expression.

Positive Social Situation: Social occurrence description including relationship and context cues generated through the use of a "Happy" emotion expression photograph. "Happy" was labelled as a positive expression.

Negative Social Situation: Social occurrence description including relationship and context cues generated through the use of an "Anger" emotion expression photograph. "Anger" was labelled as a negative expression.

The process used to generate the social occurrence descriptions associated with ambiguous, positive and negative situation will be discussed in detail in Chapter III.

\section{HYPOTHESES AND RESEARCH QUESTION}

To date we know that facial expressions are most likely both innate and controlled by cultural display rules. The display rules in Japan may be due to the culture's greater degree of emphasis on collectivisim, saving face, and the value placed on age and status. American display rules could be the result of American values of individualism, and the value place on youth 
or experiences. As Ekman (1971) suggests, the elicitors (situations) are an important part of emotion arousal. Missing from the research is information regarding which emotions will be appropriate or inappropriate in specific situations. Considering this gap, I will test the following hypotheses:

Hypothesis $1\left(\mathrm{H}_{1}\right)$ : Japanese and American subjects will judge the appropriateness of the same facial expressions of "Happiness", "Anger", and "Surprise" differently when those facial expressions are placed in ambiguous social situations.

Hypothesis $2\left(\mathrm{H}_{2}\right)$ : Japanese and American subjects will judge the appropriateness of the same facial expressions of "Happiness", "Anger", and "Surprise" differently when those facial expressions are placed in positive social situations.

Hypothesis $3\left(\mathrm{H}_{3}\right)$ : Japanese and American subjects will judge the appropriateness of the same facial expressions of "Happiness", "Anger", and "Surprise" differently when those facial expressions are placed in negative social situations.

Research Question $1\left(R Q_{1}\right)$ : What labels will be placed on the expressions of "Happiness", "Anger", and "Surprise" when those expressions are placed in ambiguous, positive and negative social situations?

The value of testing these hypotheses and answering the research question is in their ability to more precisely articulate the differences between dominant Japanese and American cultures. This research will specifically focus on determining differences in appropriateness of emotion expression with regards to specific situations and on the labelling of emotion expressions in specific situations. To date, no research has been conducted that examined specific situation differences involving two cultures. Friesen (1972) was only able to validate the existence of display rules. Matsumoto (1990) and Matsumoto \& Hearn (1991) validated display rule differences for 
different cultures, although the situation descriptions used lacked context information. By categorizing situations with "positive", "negative", and "ambiguous" labels, the information gathered leads to more specific naming of cultural differences.

To summarize, the independent variables for this thesis are: facial expression, culture and social situation. The dependent variable is the perceived appropriateness of the facial expression when the expression is placed in social situations.

In the next chapter I shall describe the methods employed to gather the data and the modes of statistical analysis. 


\section{CHAPTER III}

\section{METHODOLOGY}

This chapter details the operational definitions and methods of observation used in this study; in addition, this chapter describes sample characteristics, instrument development, instrument distribution, and subject post interview procedure.

This study was conducted in two distinct phases. The first phase was preliminary research and the second phase was quasi-experimental. In Phase I, data were collected to generated a list of social situations where the expressions of "Happiness", "Anger" and "Surprise" were deemed appropriate by both Japanese and American subjects. The Phase II measurement instrument was developed based upon data gathered in Phase I. Phase II of the study was designed to judge the perceived appropriateness of facial expressions in social situations. The method involved regarding each questionnaire for both cultures will be discussed under each subheading.

\section{THE SAMPLE}

The studied included the use of two different measurement instruments, each used respectively in Phase I and Phase II. The sample for the first phase of the study for both cultures consisted of a total of thirty (30) male and female students attending two large universities. Both universities 
are located in major cities in Oregon. To attempt to avoid gender counfound, the sample for the second phase of the study for both cultures included only female students. Of the 103 subjects from both cultures who participated in the second section of this study, 92 were between 18 and 35 years of age. Since no subjects were used in both Phase I and Phase II, no confound was created.

\section{Japanese Population Characteristics}

The Japanese students who participated in the first section of the study attended Tokyo International University (TIU) at Willamette University (WU) in Salem, Oregon. TIU is a sister college to WU and is located on the same campus. Once Japanese students became acclimated to the area, language, and lifestyle, they were allowed to enroll in WU courses.

The Japanese students who participated in the second section of the study attended Portland State University (PSU). They were either enrolled in English as a Second Language (ESL) Courses on their own accord, or were participating in the American Heritage Association Exchange Program. As a part of this program, they were attending PSU's ESL courses.

Of the 51 Japanese students who participated in the second phase of the study, only $4.8 \%$ had been in the United States more than 4 years. Of all of the Japanese students who participated in the second phase of the study, only one person had studied English more than eight years. Standard English education in Japan is eight years. 
American Population Characteristics

The American students who participated in the first section of this study were students attending Portland State University, enrolled in either Basic Speech Communication or Public Speaking courses.

The sample for the second phase of the study were different individuals drawn from the same pool of subjects. Of the 52 students involved in the study, $100 \%$ were born and raised in America. English is their native language.

\section{INSTRUMENT AND METHOD}

The Japanese and American (Caucasian) students for each phase of the study received identical questionnaires, with the exception that the photographs were specific to each culture; the Japanese judged pictures of Japanese females while the Caucasians judged pictures of Caucasian females. No pictures were judged cross-culturally. The photographs were taken from a slide set named "Japanese and Caucasian Facial Expression of Emotion" (JACFEE) 3 The set includes 56 photos, 12 of which were used in this study. The photos used included two different Caucasian females and two different Japanese females displaying expressions of "Happiness", "Anger" and "Surprise". There were a total of twelve different posers, six from each culture. The photographs used were of posed expressions in an attempt to ensure the emotion expressions were pure, rather than blended emotion expressions. The photographs have been coded using Ekman's

3 JACFEE is a slide set made available by David Matsumoto of San Francisco State University. For information about the availability of the slides contact David Matsumoto at San Francisco State University, Department of Psychology, 1600 Holloway Avenue, San Francisco, CA 94132. 
emotion expressions. The photographs have been coded using Ekman's Facial Action Coding System (FACS). The photographs have been tested previously (Matsumoto, in press; Matsumoto \& Hearn 1991; Matsumoto, 1990) and have .91 coder reliability.

\section{Instrument--Phase |}

Phase I of the study was conducted using a questionnaire and defined the operation by which positive, negative and ambiguous social situations were created. Each questionnaire had three statements to which the subjects responded (See Appendix A). The subjects in each culture were asked to recall an event where they had seen a person make an expression like the one in the picture. Or, the subjects could report an event where they had made a face like the one in the photograph. The subjects were given 15 minutes to respond to one expression each of "Happiness", "Surprise" and "Anger". The photographs consisted of six posers for each culture. Two different posers in each culture expressed "Happiness", a second different set of posers expressed "Anger" and the third different set of posers expressed "Surprise". Two different posers were used ensure that the photographs were not the cause of measured cultural differences. Additionally, several posers were used to prevent the subjects from becoming predisposed to an expression because they had seen it on the previous posers face.

These three general expressions of "Happiness", "Anger" and "Surprise" were chosen through a critical review of previous emotion expression research (Ekman \& Friesen, 1971; Boucher \& Carison, 1980; 
Ekman et al., 1978). The results of the critical review showed that the expression of "Happiness" was scored with the highest level of agreement $(91 \%)$ for positive expressions, regardless of culture. "Anger" was scored in the critical review with the highest level of agreement (70\%) for negative expressions, regardless of culture. "Surprise" was chosen for the study as an ambiguous expression because it scored the lowest level of agreement $(62 \%)$ in the critical review. "Happiness" was then labelled as a highly congruent positive expression. "Anger" was then labelled as a highly congruent negative expression. "Surprise" was then labelled as a highly ambiguous expression.

The photographs were separated into four sets of pictures so each culture had two sets. Each set used different posers and included a poser expressing "Happiness", a second poser expressing "Anger" and a third poser expressing "Surprise". All of the posers were female and all posers appeared only once across all sets of photos. Half of the subjects within each culture received one of the two different sets of pictures. Again, the Japanese subjects only saw Japanese posers while the Caucasian subjects saw only Caucasian posers.

\section{Procedure--Phase I}

The measurement instrument used in the study was pretested with 8 to 10 subjects from each culture. Half of the subjects within each culture received one of the two different sets of pictures. Again, the Japanese subjects only saw Japanese posers while the American subjects saw only American posers. The pre-test results indicated that the subjects understood 
the questions and directions in the questionnaire. It took approximately five (5) minutes longer for the Japanese students to respond to the photographs than the American subjects. The Japanese students were allowed to respond either in Japanese or English. After taking the pre-test, the Japanese students requested the questionnaire be written in their native language. This recommendation was followed for Phase II of this study. After the pre-test was completed, the questionnaire was distributed to 15 Japanese students at TIU and 15 American students at PSU. The Japanese students filled out the questionnaires during a monthly evening peer group meeting. The American subjects completed the questionnaire during their Basic Speech Communication course.

\section{Phase I Results}

The situational descriptions given in Phase I of the study were analyzed for consistencies across both cultures. The responses generated by the male and female subjects from both cultures showed no apparent gender differences in situation generation. The responses that were most common to both cultures were used in Phase II.

For both American and Japanese subjects, the most common response for the expression of "Happiness" was "defeating an opponent in a sporting event". The sports mentioned varied in the responses. But the common theme among the responses was victory.

The most common response for the expression of "Surprise" for both cultures was "being in class and forgetting there was a test today". And for the expression of "Anger", the subjects' most common response was "being 
in a social situation with friends, and disagreeing with one of them". Again, the subjects mentioned various social situations like parties, studying with friends, and having lunch. However, among the situations reported, being at a party was the most common response.

\section{Instrument--Phase II}

The situation descriptions that were generated in Phase I of this study were then used as stimulus material in the quasi-experimental study. Phase II also relied on a questionnaire format (See Appendices B and C). Each subject was asked to look at a photograph, read the corresponding social situation description, and then report on the appropriateness of the facial expression to the social situation. This was the measurement of the dependent variable.

As discussed earlier, "Happiness" was labelled as a positive expression, "Anger" as a negative expression and "Surprise" as an ambiguous expression. The situations generated in Phase $I$ of this study were consequently labelled as such: The situation from the "Happy" photograph was labelled as a positive situation, the situation description from the "Anger" photograph was labelled as a negative situation, and the situation generated from the "Surprise" photograph was labelled as an ambiguous situation.

Three different versions of the questionnaire were then developed as follows. The situation descriptions in all three questionnaires remained constant. The expression photographs were rotated, in round-robin fashion, so that the appropriateness of each expression could be rated in each 
situation. For example, the expression of "Happiness" was not only rated in a positive situation, but also in the negative and ambiguous situations. The same is true for the expressions of "Anger" and "Surprise". In versions $\# 1, \# 2$, and \#3, the situation descriptions were as follows.

Statement One "You are at a party with your friends. You and one of your friends disagree on something".

Statement Two "You're sitting in class when your teacher begins handing out a midterm examination. You forgot the test is scheduled for today".

Statement Three "You are playing your favorite sport and have just defeated your opponent".

In version \#1, the photographs were in the following order: "Happy", "Angry", "Surprised". In version \#2, the photographs were in the following order: "Surprised", "Happy", "Angry". In version \#3, the photographs were ordered: "Angry", "Surprised" and "Happy". Table II summarizes the composition of the three different questionnaires. Table III presents the sample size for each version of the questionnaire.

TABLE \|

VERSIONS OF QUESTIONNAIRES BY EXPRESSION AND SITUATION Situation Description (For all Versions) -.. $\quad$ ++ ??

Version 1 Expressions $H \quad A \quad S$

$\begin{array}{llll}\text { Version } 2 \text { Expressions } & S & H & A\end{array}$

Version 3 Expressions A $\quad S \quad H$

$\begin{array}{lll}H=\text { Happy } & S=\text { Surprise } & A=\text { Anger } \\ \cdots=\text { Negative } & ++=\text { Positive } & ? ?=\text { Ambiguous }\end{array}$ 
TABLE III

\section{SAMPLE SIZE BY QUESTIONNAIRE VERSION WITHIN EACH CULTURE

$\begin{array}{ccc}\text { Questionnaire } & \text { Questionnaire } & \text { Questionnaire } \\ \# 1 & \# 2 & \# 3\end{array}$

$\begin{array}{llll}\text { American Subjects } & 17 & 17 & 18 \\ \text { Japanese Subjects } & 17 & 16 & 18\end{array}$

The photographs used were the same sets of photographs used in Phase I of the study. They were again separated in the same fashion as Phase I of the study.

The subjects in both cultures were asked to read the situation description and look at the corresponding photographs. They were then to rate the appropriateness of the expression for that situation. To report on the level of appropriateness, a 5 point Likert-type scale was used. In the scale, $0=$ very inappropriate, $2=$ neutral, $5=$ very appropriate. The subjects were then asked to choose the expression label that most closely matched the expression in the picture. The label was chosen from a list of: "Happy", "Sad", "Angry", "Surprise", "Afraid", and Disgust". These label were chosen because previous research (Boucher \& Carlson, 1980; Ekman, Sorenson, \& Friesen, 1969; Ekman et al., 1987) has suggested that these six expressions are universally recognized. Subjects were permitted to write in another expression label. Each subject completed this process for expressions 1,2 and 3 , then answered some brief demographic questions. Demographic questions concerned: age, country of birth, length of stay in United States, and number of years studying English. 
As suggested in Phase I of this study, the questionnaires for the Japanese subjects were translated into Japanese by a native Japanese speaker. The questionnaires were then back-translated by a different native Japanese speaker to ensure the accuracy of the original translation. The results showed the original translations were accurate.

\section{Procedure--Phase II}

The American subjects completed the questionnaires during their Basic Speech Communication, or Public Speaking class periods. The task took on the average of 7 minutes for the students to complete. The 37 Japanese subjects who were part of the American Heritage Exchange Program completed their questionnaires during an evening group meeting. It took on the average of 10 minutes for the Japanese students to complete the task. Nine of the Japanese students were graduate assistants at Portland State University and this group completed the questionnaires following their meeting. The remaining Japanese students completed the questionnaires after their ESL classes.

Every fourth American subject was briefly interviewed after their communication class periods in an attempt to determine the influence of context or relationship on appropriateness ratings. All of the Japanese subjects from the American Heritage Association were interviewed during the course of their evening meeting to also determine the influence of context or relationship on appropriateness ratings. However, the language barrier with these subjects made it impossible to complete the interviews with twelve students. Every fourth Japanese subject from the ESL classes 
was interviewed following their ESL class. Because of time constraints, none of the Japanese Graduate Assistants were interviewed. All subjects were asked what questionnaire number they had, and were asked to report their responses. After each response was recorded, they subject was asked to expand on why this expression was appropriate or inappropriate in this situation. The interviewer then probed to learn if the context or the relationship with the other person in the situation influenced the response.

The same question regarding appropriateness was asked for all three situations. However, the attempt to ascertain the influence of context or relationship changed for each question. A probing question asked for Situation Two was, "some times you have classes with friends, but other times you don't, Would you give the same appropriateness rating to this expression if you had friends in this class with you?". The subjects were then asked to answer why the presence of a friend would or would not change the appropriateness rating. A probing question asked for Situation Three was, "Would you give the same appropriateness rating if you opponent was your friend?" The subjects were then asked to explain their response.

The results of the interviews did reveal some interesting information. Almost all of the responses for both cultures to the questions of why an expression is inappropriate or appropriate centered around the context or the relationship with the other people in the situation description. The Japanese and American subjects responded in similar fashion for all three situations. The primary consideration for the subjects when responding to questions regarding appropriateness of expressions in Situation One was 
the fact that they were at a party. Being at the party dictated what expressions were acceptable or unacceptable. In other words, context was the primary consideration in Situation One when measuring appropriateness. The same is true for Situation Three. Both Japanese and Americans reported that because the situation involved competition, all the rules about expressions changed. The responses about Situation Two were not so explicit. The responses from both cultures varied as to the influence of the relationship of the people within the situation on appropriateness, and they also varied greatly on the influence of the context of a classroom situation. Apparently appropriateness is context dependent, and possibly relationship dependent.

Chapter IV includes the results of the data analysis, discussions regarding the possible meanings of those results, and acceptance or rejection of the research hypotheses. 
CHAPTER IV

DATA RESULTS

Chapter IV presents the findings based upon the data gathered through the methods described in Chapter III. The statistical analyses tested each of the of the three research hypotheses. The chapter concludes by reporting the frequency data of the labelling exercise.

\section{HYPOTHESES TESTING}

The Statistical Package for the Social Science (SPSSx) was used to analyze the data statistically and test Hypothesis 1,2 and 3. Again, the Hypotheses were:

Hypothesis $1\left(\mathrm{H}_{1}\right)$ Japanese and American subjects will judge the appropriateness of the same facial expressions of "Happiness", "Anger", and "Surprise" differently when those facial expressions are placed in ambiguous social situations.

Hypothesis $2\left(\mathrm{H}_{2}\right)$ Japanese and American subjects will judge the appropriateness of the same facial expressions of "Happiness", "Anger", and "Surprise" differently when those facial expressions are placed in positive social situations.

Hypothesis $3\left(\mathrm{H}_{3}\right)$ Japanese and American subjects will judge the appropriateness of the same facial expressions of "Happiness", "Anger", and "Surprise" differently when those facial expressions are placed in negative social situations. 


\section{Hypothesis 1 Test}

An analysis of variance (ANOVA) was computed in an attempt to validate the existence of a significant difference in the two culture's responses for each situation. In this study's case, the ANOVA is the statistical test of choice because the research design for this thesis involved analyzing the differences of 2 independent samples and included simultaneous relationships among 3 independent variables. Culture, facial expression and social situation were the independent variables. The dependent variable was the appropriateness of expressions. Japanese and American subjects comprised the 2 independent samples. The following ANOVA results were computed testing Hypothesis 1.

\section{TABLE IV}

ANOVA RESULTS OF AMBIGUOUS SITUATION (HYPOTHESIS 1)

\begin{tabular}{llll} 
Variable & $F$ & D & df \\
\hline Culture & 00.04 & ns & 1 \\
Facial Expression & 59.95 & .001 & 2 \\
Interaction effect & 01.17 & ns & 2 \\
Main Effects & 40.00 & .001 & 3
\end{tabular}

These results indicate Hypothesis 1 was not supported by the Analysis of Variance. The ANOVA is designed to "compare" ingroup variance to between group variance. The statistical procedure investigates the amount of variation in the Japanese appropriateness ratings and the amount of variation in the American appropriateness ratings. Those 
variances are then compared to the variation between the two groups. If there is a large enough between group difference, a significant $F$ statistic, and corresponding significant $p$ value $(p<05)$ result. For Hypothesis 1 to be accepted, there must be a significant $F$ statistic and significant corresponding $p$ value $(p<.05)$ for the variable "Culture". The $p$-value for "Culture" is .836, and consequently reported as n.s (not significant) in Table IV. The closer the $p$ value is to 1.0 , the less difference or variation there is between the groups. In this case, the $p$ value denotes there was no detectable difference between the Japanese and American subject's appropriateness ratings with regards to ambiguous situations. Therefore, Hypothesis 1 can not be validated and the results indicate a failure to reject the null hypothesis.

The results of the ANOVA for $\mathrm{H}_{1}$ contain a significant $\mathrm{p}$ value for the variable "Facial Expression". This statistic means that in the ambiguous situation the ratings of appropriateness varied significantly from expression to expression. In other words, expression appropriateness ratings for "Happy" varied significantly from both "Anger" and "Surprise" expression appropriateness ratings. Table $V$ presents the appropriateness rating group means for each expression. The information in this table shows how the expressions were rated as a group by the Japanese and American subjects for each situation.

The higher values listed in Table $V$ correspond to greater levels of appropriateness for the expression in the situation. These group means are reported because although the analysis of variance indicated overall 


\section{TABLE V}

APPROPRIATENESS RATING GROUP MEANS BY EXPRESSION AND SITUATION FOR JAPANESE AND AMERICAN SUBJECTS

Anger Happy Surprise

$\begin{array}{llll}\text { Ambiguous situation } & 2.85 & 0.42 & 3.25 \\ \text { Positive Situation } & 0.42 & 1.65 & 3.23 \\ \text { Negative Situation } & 1.41 & 1.14 & 1.71\end{array}$

differences for expression, the ANOVA can not reveal pair-wise expression differences. Therefore, by calculating and reporting the group means, a follow up test can be performed that will reveal significant pair-wise expression differences. This test, called a Scheffe Test, was chosen because computing an a-posteriori Scheffe provides a test where the probability of a type one error for any pair comparison will not exceed the original ANOVA level of significance. The Scheffe procedure shown in Figure 3 calls for computation of an F-statistic using the following formula.

$$
F=\frac{\left(X_{1}-X_{2}\right)^{2}}{\operatorname{MS}_{W}\left(\frac{\left.1--\frac{1}{n_{1}}\right)}{n_{2}}\right)(k-1)}
$$

Figure 3. Scheffe formula used to compute follow-up pair-wise expression differences. $X_{1}$ and $X_{2}$ are the group appropriateness means reported in Table $V, M S_{W}$ is the mean square statistic from the original ANOVA, and, $n_{1}$ and $n_{2}$ are the number of responses in each group mean category. $k=$ degrees of freedom.

All results of the Scheffe test were hand calculated. The post-hoc Scheffe test confirmed there are significant differences for 2 of 3 expression pairs. The results in Table VI indicate that in ambiguous situations, "Anger" 
and "Happy" expressions were rated significantly different as were "Surprise" and "Happy" expressions. "Anger" and "Surprise" were not rated significantly different.

\section{TABLE VI}

\section{FOLLOW-UP SCHEFFE PAIR-WISE COMPARISON RESULTS} IN AMBIGUOUS SITUATION FOR JAPANESE AND AMERICAN SUBJECTS

Expression

Pairs

Anger/Happy

Surprise/Happy

Anger/Surprise
F

Statistic

$F=37.25$

$F=50.56$

$F=01.01$ $p<$

0.05

0.05

n.s

This information is very important because the statistical results from the ANOVA variables of "Culture" suggest that both cultures gave similar appropriateness ratings for the different expressions in the same situations. However, each expression for the pairs of "Anger"/"Happy" and "Surprise"/"Happy" received significantly different ratings from each other. These results suggest that the expressions in the ambiguous situations were different enough to detect a variance in cultural responses, if there indeed would have been a variance in culture.

\section{Hypothesis 2 Test}

The statistics corresponding with Hypothesis $2\left(\mathrm{H}_{2}\right)$ show a similar significant expression statistic and a second significant statistic, although the "Culture" statistic is insignificant (See Table VII). As with Hypothesis 1, the ANOVA results indicate Hypothesis 2 is not supported because the statistic 
for the variable "Culture" is not significant. The $p$ value for "Culture" is .612 and is reported in Table VII as n.s. (not significant), meaning the two groups gave similar responses. These results suggest that there is no difference between Japanese and American cultures regarding appropriateness ratings in positive situations.

\section{TABLE VII}

\section{ANOVA RESULTS OF POSITIVE SITUATION} (HYPOTHESIS 2)

$\begin{array}{llll}\text { Variable } & F & 0< & \text { df } \\ \text { Culture } & 00.26 & \text { n.s. } & 1 \\ \text { Facial Expression } & 58.57 & .001 & 2 \\ \text { Interaction } & 05.57 & .005 & 2 \\ \text { Main effects } & 39.10 & .001 & 3\end{array}$

The "Facial Expression" statistic is significant at the .001 level, as it was in the "ambiguous situation" $\left(H_{1}\right)$ ANOVA resuits. Follow-up Scheffe tests were again performed using the Appropriateness Rating Group Means for Positive Situations found in Table V. The results of the Scheffe test, reported in Table VIII indicate all expressions were rated significantly different from each other.

"Anger" was rated significantly different from "Happy" as well as "Surprise". And, "Happy" expressions were rated significantly different from "Surprise" expressions. Again, this information is important because it suggests there was a significant enough difference in the subjects' 


\section{TABLE VIII}

\section{FOLLOW-UP SCHEFFE PAIR-WISE COMPARISON RESULTS} IN POSITIVE SITUATION FOR JAPANESE

\section{AND AMERICAN SUBJECTS}

Expression

Pairs

Anger/Happy

Surprise/Happy

Anger/Surprise
$F$

Statistics

$F=10.81$

$F=17.86$

$F=56.40$ $p<$

0.05

0.05

0.05

expression appropriateness ratings to detect a possible cultural difference, if one had existed. These results are even more powerful than the results for $\mathrm{H}_{1}$ because all expression pairs were given significantly different ratings.

The second significant statistic from the ANOVA results for $\mathrm{H}_{2}$. is the interaction effect. This significant finding indicates that in the positive situation there exists some special effects that need to be considered. These special effects are due to the combination of the culture and expression factors. The interaction results indicate that whatever differences exist between expression factor levels for the Japanese apparently are not the same as the differences found for Americans. This implies there is a significant variance in culture for this situation (positive) even after the main effect variations have been accounted for. By graphing the Japanese and American appropriateness rating means by expression, we can see the significant interaction. (See Figure 4).

The significant interaction finding $(p<.05)$ corresponds to the Japanese reporting higher or more appropriate ratings for "Surprise" in positive situations than the Americans. But, the Japanese also reported 
lower appropriateness ratings for "Happy" expressions than Americans. The "Anger" expressions were rated similarly (.52 Americans, .31 Japanese).

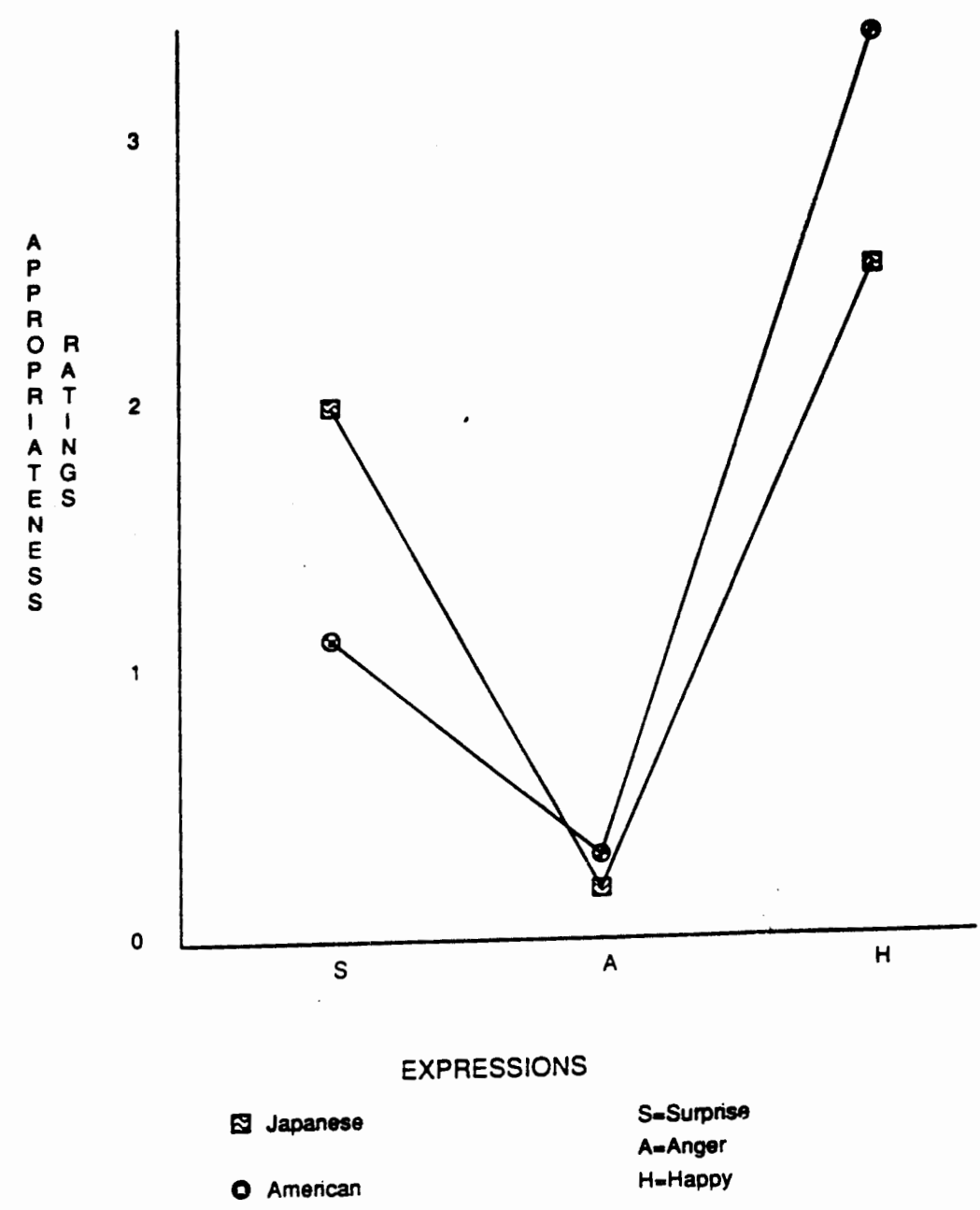

Figure 4. Significant interaction effect of Japanese and American appropriateness ratings in positive situation.

With the significant interaction results it is acceptable to suggest rejection of the null hypothesis and partial acceptance of $\mathrm{H}_{2}$. These results suggest Japanese and American differ significantly in regards to positive 
situation appropriateness ratings for "Happy" and "Surprise" expressions. The possible explanations for this result will be discussed in Chapter V.

Hypothesis 3 Test

The ANOVA statistics corresponding with Hypothesis 3 show no significant results for culture, facial expression, or interaction effects. (See Table IX) Therefore, Hypothesis 3 was not supported.

\section{TABLE IX}

ANOVA RESULTS OF NEGATIVE SITUATION (HYPOTHESIS 3)

\begin{tabular}{llll} 
Variable & $F$ & $D<$ & df \\
\hline Culture & 0.003 & n.s. & 1 \\
Facial Expression & 1.474 & n.s. & 2 \\
Interaction & 0.447 & n.s. & 2 \\
Main effects & 0.983 & n.s. & 3
\end{tabular}

To summarize the section of hypothesis testing, the ANOVA and Scheffe test results indicate: failure to support Hypothesis 1, partial acceptance of Hypothesis 2, and failure to support Hypothesis 3. The additional statistics that follow will assist in the answering of Research Question 1.

\section{RESEARCH QUESTION}

As noted in Chapter III, the subjects were also asked to label each of the three expressions. SPSSx was used to compute the percentage of 
responses for each culture in each of the nine pairings of situations and expressions. (See Table X). To reiterate, Research Question 1 asked:

What labels will be placed on expressions of "Happiness", "Anger", and "Surprise" when those expressions are placed in ambiguous, positive and negative social situations?

The results produced several points worth noting. One hundred percent of the American subjects labeled "Happy" as "Happy" in a positive situation. Neither culture gave consistent labels for "Happy" in an ambiguous situation. The responses varied from: "Happy", 41\%; "Afraid", 17\%; "Surprise", 11\%; and "Embarrassed", 11\% for the American subjects. While the Japanese responded as: "Happy", 25\%; "Surprised", 25\%; "Angry", 12.5\%; and "Forcing a smile", 12.5\%. The responses to "Happy" in a negative situation varied for both cultures, with neither culture having more than $41 \%$ of the subjects label the expression as "Happy". These results seem to indicate the subjects rely on the situation cues to label the expression, even if the expression is contradictory to the situation.

The labels associated with the "Anger" expression are interesting. In positive situations $29 \%$ of the Americans and $25 \%$ of the Japanese labeled "Anger" as "Disgust". A puzzling aspect of the "Anger" labels is in regard to the Japanese responses. Thirty eight percent (38\%) of the Japanese subjects labeled "Anger" as "Glad". Only $12.5 \%$ of the Japanese subjects labeled "Anger" as "Anger". The remaining Japanese subjects labeled "Anger" as "Disgust". "Anger" was the expression both cultures had the most 


\section{TABLE X}

\section{EXPRESSION LABEL RESPONSE PERCENTAGES FOR JAPANESE AND AMERICAN SUBJECTS FOR EACH PAIRING OF EXPRESSION AND SITUATION}

\section{Expression \\ and Situation}

Happy in ?

Happy in +

Happy in ---

Anger in?

Anger in +

Anger in ---

Surprise in ?

Surprise in +

Surprise in -.-

$+=$ Positive Situation

\section{American}

Responses

Happy

Afraid

Surprise

"Embarrassed"

Happy

Happy
Surprise
Other

Anger

Disgust

Surprise

Anger

Disgust

Anger

Disgust

Surprise

Surprise

Sad

Surprise
$\%$

41.0

17.0

11.0

11.0

100.0

35.0

35.0

30.0

71.0

17.0

12.0

35.0

29.0

72.0

27.0

100.0

82.0

11.0

94.0
Japanese

Responses

Happy

Surprise

Anger

"Forced Smile" 12.5

Happy $\quad 72.0$

Glad $\quad 17.0$

"Forced Smile" 29.0

Happy $\quad 07.6$

Afraid $\quad 17.6$

Surprise $\quad 11.8$

Angry $\quad 30.0$

Disgust $\quad 23.0$

Afraid $\quad 17.0$

"Confused" $\quad 11.8$

Surprise $\quad 11.8$

Glad $\quad 37.5$

Disgust $\quad 25.0$

Anger $\quad 12.5$

Anger $\quad 44.0$

Disgust $\quad 44.0$

Surprise $\quad 89.0$

Surprise $\quad 100.0$

Surprise $\quad 75.0$

Anger $\quad 12.0$

- = Negative Situation

? = Ambiguous Situation 
difficult time labeling. Its highest percentage of agreement in labels was $72 \%$ by the American subjects in "Anger" in a negative situation. ("Anger" in an ambiguous situation was a close second at $71 \%$ for American subjects). The Japanese consistently labeled "Anger" as "Disgust" and did so marginally less often than they labeled "Anger" as "Anger". The Japanese highest level of agreement when labeling "Anger" was only 44\%, corresponding to "Anger" in a negative situation. In this situation, the Japanese labeled "Anger" as "Disgust", "Afraid", "Confused", and "Surprised". The results suggests Japanese subjects have difficulty identifying the negative expression of "Anger".

Regardless of the situation, both cultures agreed on the labeling of the "Surprise" expression. One hundred percent of the Japanese subjects labeled the expression of "Surprise" as "Surprise" for the positive situation. Of the Americans, $82 \%$ of the subjects labeled "Surprise" as "Surprise". The remaining US subjects labeled "Surprise" as "Happy". For both cultures, "Surprise" expressions received the most labels as "Surprise", regardless of the situation. This finding is inconsistent with findings of earlier researchers (Boucher \& Carlson, 1980; Ekman \& Sorenson, 1969; Ekman et al., 1987) who found the "Surprise" expression was labelled as "Surprise" with the least amount of accuracy.

The next chapter will discuss the lack of support for 2 of the 3 research hypothesis. Focus will be centered on the possible interpretation of the statistical findings. In addition, limitations of the study and directions for future study will be identified. Descriptive data from the research results 
will be brought to bear on reasoning why Hypotheses 1,2 , and 3 were not supported. 


\section{CHAPTER V}

\section{DISCUSSION}

This chapter presents an analysis of the results reported in Chapter IV. Discussion centers on the failure to find support for Hypothesis 1 and 3 , and the discovery of only partial support for Hypothesis 2. In addition to examining possible explanations based in the literature for the nonsignificant results, limitations of the study due to design and execution are also presented. The chapter concludes with suggestions for future research.

\section{GENERAL ANALYSIS OF EVIDENCE}

The general results of this study do not support Ekman's NeuroCultural Theory of Emotion. With one minor exception, no cultural differences were found. There are several possible explanations for the failure to find support for the research hypotheses. First, this thesis is based on Ekman's Neuro-Cultural Theory, which quite possibly contains theoretical problems. Second, the stimulus material used is based on the theory of universal facial expressions. This theory may also need reinvestigation. Third, the thesis study itself may contain weaknesses damaging its internal validity. These explanations, plus others, are addressed under each subheading. 


\section{DISCUSSION OF HYPOTHESES}

The data results, as reported in Chapter IV, show there were no significant differences for 2 of the 3 hypotheses. Previous literature suggested Hypotheses 1,2 and 3 should have been supported based on the presumed existence of cultural display rules. However, the statistical results of this study do not support those findings.

\section{Hypotheses 1 and 3}

Hypotheses 1 and 3 were not supported. The hypotheses may not be supported because under the Neuro-Cultural Theory, Ekman's concept of display rules may not be sufficiently accounting for subtleties and complexities of emotion display and interpretation. In other words, the cultural richness involved with displaying and interpreting emotion is not full appreciated. The lack of consideration of cultural richness will certainly obscure the cultural meaning of expressions. Ekman's Neuro-Cultural Theory explains the effect of cultural display rules on emotion expressions will be either: intensifying, de-emphasizing, neutralizing, or masking of the expression. These facial behavior outcomes are based on four "defining" characteristics of a situation. (See page 25). Most likely, there are more considerations people take into account, consciously or otherwise, before expressing or interpreting an emotion. This explanation based on the theoretical problem associated with the Neuro-Cultural Theory could explain why no significant results were found for Hypotheses 1 and 3.

In addition to possible weaknesses of the Neuro-Cultural Theory, flaws may also exist within Ekman's (1987) theory of Universality of 
Emotions. Ekman's theory suggests that the labels associated with six expressions are universal. Photographs of facial movement can serve as icons for expression labels. However, there may be connotations or figurative meanings associated with each expression that are very different from the denotative or dictionary meaning. An expression may be labelled as "Happy" in two different cultures, but the connotation may be different for each culture, or even for individuals within the same culture. For example, Japanese may display a "Happy" expression to cover disappointment, and Americans may display "Happy" because they truly feel good. The expressions are the same; the associated meanings are different. These connotative meanings associated with expression labels probably affect the appropriateness of expressions in certain situations. This study predicted cultural differences based on denotative expression labels and did not consider the possible influence of figurative meanings. In fact, the subjects' responses may have been determined by the connotative or implied meanings of expressions. This notion is supported when examining the Japanese write-in response of "Glad" in the "Happy" expression labelling exercise. Seventeen percent of the Japanese subjects labelled "Happy" expressions as "Glad" According to post-interviews, "Glad" is a term used by Japanese to describe when something is good. According to Watanabe (personal communication, April 28, 1993), in a situation where an American would say " I'm happy for you", a Japanese may use "glad". The Japanese term of "Happy" is associated with a gift or luck. For example, winning the lottery would make a Japanese person "Happy", while getting an A on a paper would make them "Glad". Watanabe (personal communication, April 
$28, .1993)$ says, even in situation where happiness is the result of one's effort, one does not attribute it to effort. Instead one expresses their indebtedness. This example suggests that further refinement needs to be given to the labels associated with expressions, and that connotative meanings of expression labels should be investigated. This also suggests the meanings of expression labels currently used may not be as universal as suggested by Ekman et al. (1987).

The results of the labelling exercise also suggest the subjects rely on context cues to label the expressions. Data reported in Table $\mathrm{X}$ indicate the expressions were labelled most 'accurately' when placed with the situation from which they were generated originally: "Happy" in a positive situation, "Anger" in a negative situation, and "Surprise" in an ambiguous situation. Matsumoto (1990) suggested that context and emotion expression are so closely tied that one cannot function without the other. This would make investigating expression appropriateness without context a futile effort. Since Ekman et al. (1987) suggested the universality of expressions and their study did not include context descriptions, the results of that work should be interpreted cautiously.

A further critique of Ekman's universal expressions and expression labels again suggest the labels are too elementary. The universal expressions suggested by Ekman et al (1987) do not include expression tropes such as: irony, sarcasm, teasing, facetiousness, embarrassment or confusion. These tropes can be derived by subjects from a "Happy" expression if a figurative meaning could be construed simply by placing the expression within situation context. As discussed earlier, expression labels 
are most likely context dependent. Therefore, Ekman's failure to use context descriptions in his study where subjects labelled expressions may have created a list of suggested universal expressions that is neither as reliable or as valid as previously thought.

There are other possible explanations for the lack of support for the Hypotheses. First, the nonsignificant findings associated with $\mathrm{H}_{1}$ and $\mathrm{H}_{3}$ could be interpreted as support for shared cultural norms. If there were no differences between the cultures, it is possible they share or have similar cultural display rule norms for the situations and expressions depicted in this study. Or, the nonsignificant findings for $\mathrm{H}_{1}$ and $\mathrm{H}_{3}$ could be explained by suggesting that cultural display rules do not exist. If there are no differences between the cultures' appropriateness ratings, then no rules are controlling the perceived level of acceptability of the expression for that situation.

Other explanations for the lack of support for the research hypotheses centers about the internal validity of the thesis itself. The results may have been non-significant because the 5-point Likert scale used to judge the appropriateness of expressions was not discriminating enough to detect differences. This issue will be discussed in the limitations section, later in this chapter.

\section{Hypothesis 2}

Hypothesis 2 was only partially supported. This may be caused by the same theoretical issues discussed with Hypotheses 1 and 3. Or, there are other possible considerations. 
The differences found in positive situations $\left(\mathrm{H}_{2}\right)$, ironically indicate some cultural display rule norms may be the same for the Japanese and American cultures. Significant differences (interaction effect) were found between Japanese and American subject's appropriateness ratings for positive situations $\left(\mathrm{H}_{2}\right)$ with regards to "Happy" and "Surprise" expressions. In positive situations, the Japanese rated "Surprise" as more appropriate than the Americans. The Americans rated "Happy" expressions in positive situations as more appropriate than the Japanese. This difference can be explained by examining the results for "Happy" and "Surprise" more closely. Statistical results indicate the Japanese consider "Surprise" as appropriate in all situations. ANOVA results for the positive situation shows a significant difference for Japanese and American subjects. The ordinal (rank) interpretations of the expression are the same for both cultures (See Figure 4). This suggests both cultures agree the most appropriate expression is "Happy", and the least appropriate expression is "Anger". However, as noted earlier, the Japanese gave a much higher appropriateness rating to "Surprise" than the Americans did. The Americans gave a much higher appropriateness rating to a "Happy" expression. Figure 4 indicates Japanese mean appropriateness ratings for "Surprise" and "Happy" are similar 2.05 and 2.78 , respectively, with a difference of .73 . The Americans appropriate ratings for "Surprise" and "Happy" 1.23 and 3.67, respectively differed by almost 2.5 points on a 5 point scale. It is possible the two cultures share a norm of being surprised or at least expressing surprise at something good, but it is stronger and more appropriate in Japan. 
Another possible explanation focuses on the questionable validity of the situation associated with Hypothesis 2. The context description associated with positive situations is "defeating an opponent in a sporting event". Although this situation description was generated by subjects in both cultures, it is reasonable to ask if this is really a positive situation for the Japanese subjects. The "Surprise" appropriateness ratings may have been given by the Japanese because one should be polite in this situation. A "Happy" expression would be seen as "gloating". This situation actually may be difficult or negative for a Japanese person. Then why was this situation generated by Japanese subjects as a positive one, when it is not? Demand characteristics is one possibility; the Japanese subjects may have responded with what they thought the researcher wanted, rather than what they truly thought. Or, the Japanese subjects' responses may have been affected by familiarity with American sporting events.

Gender differences may have also contributed to the results associated with Hypothesis 2. The positive situation, a sporting event, was generated by male and female subjects. However, women and men may view appropriateness differently when defeating their opponent. What is appropriate from a male point of view may not be appropriate from a female point of view. In general, women may focus more upon the game, while men, in general focus on the contest. Consequently, having male subjects participate in generating situation descriptions may have created a gender confound. In sum, when taking the stimulus material for positive situations into consideration, the results associated with Hypothesis 2 must be viewed with some skepticism. 


\section{DISCUSSION OF RESEARCH QUESTION}

For this section of the study, the subjects were asked to label expressions in the photographs. Again, the results of the task are reported in Table $X$.

Note the "Anger" expression labels in Table $X$. The Japanese subjects label "Anger" expressions as "Anger" only when there were corresponding situational cues. The same is true for "Happy" expressions for both cultures. There was little agreement of expression labels when "Happy" expressions were presented in negative and ambiguous situations. In neither culture did more than $41 \%$ of the subjects correctly label the "Happy" expression. These results suggest that context cues are important when subjects are attempting to label expressions.

"Surprise" was the expression labelled most accurately by both Japanese and American subjects regardless of the situation. Possibly, these results occurred because "Surprised" expressions are deemed appropriate in positive, negative, and ambiguous situations. Surprise may be a highly appropriate response across situations and cultures; "Surprise" may reflect a personal response to the situation, rather than an evaluation of the situation.

It is possible the percentages of 'correctly' labelled expressions were low in this study because the subjects were given the opportunity to write in other responses. Given the opportunity to write in responses, the subjects created a variety of labels that the subjects thought were more appropriate than the researcher. Both the Japanese and American subjects responded 
with write-in expression labels. The ratio of Japanese and American labels reported, including the listed and write-in responses are similar for each expression and situation pairing. For the pairing of "Happy" in an ambiguous situation, both American and Japanese subjects gave four different responses. For the pairing of "Anger" in a positive situation, both American and Japanese subjects gave 2 different responses. This similarity exists in all of the expression and situation pairings; the variance appears equivalent. The opportunity for subjects to create labels may have obscured between culture differences. Had subjects relied exclusively on the researchers labelling, the cultural variance may have been significant. The proliferation of labels offered by subjects contributes to the position that Ekman's finding of universality should be considered cautiously. Since his subjects were not given the opportunity to offer their own expression labels, Ekman may have increased reliability at the expense of validity.

\section{POST-INTERVIEWS}

The results of the post-interviews indicate context cues are important when determining appropriateness of an expression. The responses to post-questionnaire inquiry for the positive situation must be considered somewhat skewed because a leading question was unintentionally asked by the interviewer. Each subject was asked what effected the appropriateness of the expression. For the positive situation, the researcher asked "Would the appropriateness change if your opponent was your friend?". Both cultures agreed the context of the situation dictated what 
expressions were acceptable. These results support the notion that expressions are context dependent.

\section{LIMITATIONS}

One methodological issue that merits discussion is the use of a 5point Likert type scale. Matsumoto (1990) and Matsumoto \& Hearn (1991) used a nine-point Likert scale in their studies of display rules. This study used a 5-point scale. It is possible the smaller scale did not allow for enough variation between "very appropriate" ratings and "very inappropriate" ratings, making differences too minute to detect. Therefore, the scale used may only be able to detect large effects. A more discriminating measurement instrument should be used in subsequent studies.

This study only tested one positive, one negative and one ambiguous situation. Each of these situations contained a relationship cue (e.g. friend, teacher). The method used did not allow for testing of appropriateness with regards to different relationships. Therefore, it is impossible to determine if different relationships (e.g. parents, siblings, professional) would have produced different results, or if varying situation descriptions would have produced different results. The results from using only one type of situation (positive, negative or ambiguous) could be classified as "fixed effects" because the results were generated by and consequently tied to one specific stimuli. If the stimulus material used was not representative of its "family" or "class" then the effect and subsequent results cannot be 
considered as random. Future research should include more than one description in each "class" of stimuli to avoid fixed effects.

\section{FUTURE DIRECTIONS}

The results of this study imply future research on display rules is necessary, but that it is important situations include context descriptions. Since Matsumoto (1990) and Matsumoto \& Hearn (1991) were able to detect cultural differences in their studies by using only relationship cues, it is suggested their research be replicated with the inclusion of the context descriptions. Studies which include both context and relationship cues could truly validate the existence of display rules.

If the existence of display rules can be validated, it is also suggested that one context situation be tested with several different relationship cues. This information would begin to uncover the influence of relationships in regard to appropriateness of expressions. The method could also be reversed to test one relationship cue with several different context cues, to provide information on the importance of context with regards to appropriateness of expressions. No past research has investigated either of these areas.

An issue that has yet to be investigated is the effect of gender on expression appropriateness. We have seen in this study that gender may indeed influence the acceptability of emotion display. Additional research is necessary to validate this idea. 
Ekman's theory of Universality of emotion should also be revisited. This investigation should address the figurative meanings of emotion display and its impact on the labelling of expressions.

Lastly, more needs to be known about the connotative meanings of labels associated with expressions. Further investigation should explore the connotative meanings associated with expressions and expression labels. The information could contribute to the understanding of expression tropes, which are themselves figurative meanings of emotion display. This author suggest development of theory for individual cultures, then expansion to cross-cultural comparisons.

There is a great deal not known about the cultural influences on facial expressions. This thesis has attempted to provide additional knowledge on cultural differences and emotion expressions. Any avenue taken from the suggestions listed above will help reduce the scarcity of accurate intercultural emotion expression information. 


\section{REFERENCES}

Allport, F. H. (1924). Social psycholegy. Boston: Houghton Mifflin.

Argyle, M. (1988). Intercultural communication. In L. A. Samovar \& R. E. Porter (Eds.), Intercultural communication: A reader (pp 33-34). Belmont, CA: Wadsworth Publishing.

Asch, S. E. (1952). Social psychology. Englewood Cliffs, N.J.: Prentice Hall.

Birdwhistell, R. L. (1963). The kinesic level in the investigation of emotions. In P. H. Knapp (Ed.), Expression of the emotions in man. New York: International Universities Press.

Birdwhistell, R. L. (1970). Kinesics and context. Philadelphia: University of Philadelphia Press.

Boucher, J. D., \& Carlson, G. E. (1980). Recognition of facial expression in three cultures. Journal of Cross-Cultural Psychology, 11(2), 263-280.

Burgoon, J. K., Buller, D. B., \& Woodall, W. G. (1989). Nonverbal communication: The unspoken dialoque. New York: Harper \& Row.

Cathcart, D., \& Cathcart, R. (1988). Japanese social experience and concept of groups. In L. A. Samovar \& R. E. Porter (Eds.), Intercultural communication: A reader (pp 186-192). Belmont, CA: Wadsworth Publishing.

Condon, J. C. \& Yousef, F. S. (1975). An introduction to intercultural communication. NY: Macmillan Publishing.

Cuceloglu, D. (1970). Perception of facial expression in three different cultures. Ergonomics, 13, pp. 93-100.

Darwin, C. (1872). The expression of the emotions in man and animals. London: Murray.

Dickey, E. C., \& Knower, F. H. (1941). A note on some ethnological differences in the recognition of simulated expressions of the emotions. American Journal of Sociology, 47, 190-193. 
Eibl-Eibesfeldt, I. (1970). Ethology: The biology of behavior. New York: Holt, Rinehart \& Winston.

Eibl-Eibesfeldt, I. (1972). Similarities and differences between cultures in expressive movements. In R. Hinde (Ed.), Nonverbal communication. London: Cambridge University Press.

Ekman, P. (1971). Universals and cultural differences in facial expression of emotion. Nebraska Symposium of Motivation. (Volume 19, 207282). Lincoln: University of Nebraska Press.

Ekman, P. (1973). Darwin and facial expression: A century of research in review. New York: Academic Press.

Ekman, P., \& Friesen, W. V. (1971). Constants across cultures in the face of emotion. Journal of Personality and Social Psychology, 17, 124-129.

Ekman, P. \& Friesen, W. V. (1986). A new pan-cultural facial expression of emotion. Motivation and Emotion, 10(2), 159-168.

Ekman, P., Friesen, W. V., \& Ellsworth, P. (1982). What are the similarities and differences in facial behavior across cultures. In P. Ekman (Ed.), Emotion in the human face (pp. 128-143). Cambridge: Cambridge University Press.

Ekman, P., Friesen, W. V., O'Sullivan, M., Chan, A., Diacoyanni-Tarlatzis, I., Heider, K., Krause, R., LeCompte, W. A., Pitcairn, T., Ricci-Bitti, P. E., Scherer, K., Tomita, M., Tzavaras, A. (1987). Universals and cultural differences in the judgements of facial expression of emotion. Journal of Personality and Social Psycholooy, 53(4), 712-717.

Ekman, P., Sorenson, E. R., \& Friesen, W. V. (1969). Pancultural elements in facial display of emotions. Science, 164, pp. 86-88.

Friesen, W. (1972). Cultural differences in facial expressions in a social situation; An experimental test of the concept of display rules. Unpublished doctoral dissertation.

Galagan, P.A. (1990). East meets west. Training and Development Journal, $44,43-47$.

Haglund, E. (1988). Japan: Cultural considerations. In L. A. Samovar \& R. E. Porter (Eds.), Intercultural communication: A reader ( $p p$ 84-94). Belmont, CA: Wadsworth Publishing. 
Higgins, S. (1991, June 24). Compaq proves road to Japan is rocky. PC Week, p. 175.

Izard, C. E. (1971). The Face of emotion. New York: Appleton.

Klineberg, O. (1938). Emotional expression in Chinese literature. Journal of Abnormal and Social Psychology, 33, 517-520.

Labarre, W. (1947). The cultural basis of emotions and gestures. Journal of Personality, 16, 49-68.

Leach, E. (1972). The influence of the cultural context on non-verbal communication in man. In R. Hinde (Ed.), Nonverbal communication (pp. 315-344). London: Cambridge University Press.

Matsumoto, D. (1990). Cultural similarities and difference in display rules. Motivation and Emotion, 14(3), 195-214.

Matsumoto, D. (1991). Cultural influence on facial expressions of emotion. The Southern Communication Journal, 56(2), 128-137.

Matsumoto, D. (in press). American -Japanese cultural difference in the recognition of universal facial expressions. Journal of Cross-Cultural Psychologr.

Matsumoto, D. \& Ekman, P. (1989). American-Japanese cultural differences in intensity ratings of facial expression of emotion. Motivation and Emotion, 13(2), pg 143-157.

Matsumoto, D., \& Hearn, V. (1991). Cultural and emotion: Display rule differences between the United States, Poland, and Hungary. Manuscript submittted for publication.

Matsumoto, D., Wallbott, H. G., \& Scherer, K. R. (1989). Emotions in intercultural communication. In M. Asante \& W. Gudykunst (Eds), Handbook of intercultural and international communication (pp. 225246). Beverly Hills: Sage.

Motely, M. T. \& Camden, C. T. (1988). Facial expression of emotion: A comparison of posed expressions versus spontaneous expressions in an interpersonal communication setting. Western Journal of Speech communication, 52, pg 1-22.

Snapshot of the Pacific rim. (1991, October 7). Eortune, pp. 128-129. 
Tomkins, S. S. (1962). Affect imagery consciousness vol 1. The positive affects. New York: Springer.

Triandis, H. C. \& Lambert, W. W. (1958). A restatement and test of Scholsberg's theory of emotion with two kind of subjects from Greece. Journal of Abnormal and Social Psychology, 56(3), 321-328.

Understand and heed cultural differences. (1990, December). Business America, pp.26-27.

U.S. trade facts. (1990, December). Business America, p. 32.

Vinacke, W. E. (1949). The judgement of facial expression by three national-racial groups in Hawaii. The Journal of Personality, 17, 407429.

Vinacke, W. E., \& Fong, R. W. (1955). The judgement of facial expression by three national-racial groups in Hawaii: II Oriental faces. The Journal of Social Psychology, 5, 185-195. 


\section{APPENDIX A}

PHASE I QUESTIONNAIRE 
Please answer the following questions.

In what country were you born?

If you are not a native American, how long did you live in your native country before coming to the United States? less than 5 years

5 to 10 years

- 10-15 years

more than 15 years

If you are not a native American, how long have you lived in the United States? less than 2 years

2 to 4 years

- more than 4 years

Attached are three pictures. Please look at each picture and ON THIS SHEET write an answer for either question $1 \mathrm{OR}$ question 2.

1). Recall an event or occasion when you saw someone make a face like that.

A) Describe in detail the event or occasion where you saw a person make that face.

B) Also describe in detail what that person was doing when you saw that person make a face like that.

\section{$\underline{\text { OR }}$}

2). Recall an event or occasion when you have made a face like that

A) Describe in detail the event or occasion where you made that face.

B) Also describe in detail what you were doing when you made a face like that.

Please DO NOT explain what you were feeling or thought the other person was feeling, but rather describe what situation you or the other person was in. Please answer as you would if you were in your NATIVE country. Feel free to respond in your native language.

\section{PICTURE \#1}

A)

B) 
1). Recall an event or occasion when you saw someone make a face like that.

A) Describe in detail the event or occasion where you saw a person make that face.

B) Also describe in detail what that person was doing when you saw that person make a face like that.

\section{$\underline{\text { OR }}$}

2). Recall an event or occasion when you have made a face like that.

A) Describe in detail the event or occasion where you made that face.

B) Also describe in detail what you were doing when you made a face like that.

Please DO NOT explain what you were feeling or thought the other person was feeling, but rather describe what situation you or the other person was in. Please answer as you would if you were in your NATIVE country. Please feel free to answer in your native language.

\section{PICTURE \#2}

A)

B)

PICTURE \#3

A)

B) 
APPENDIX B

PHASE II QUESTIONNAIRE FOR

AMERICAN SUBJECTS 
Please read the following stories and answer the questions below each picture. 1. You are at a party with your friends. You and one of your friends disagree on something.

Circle the number that corresponds with how appropriate it would be for your friend to make a face like the one pictured above.

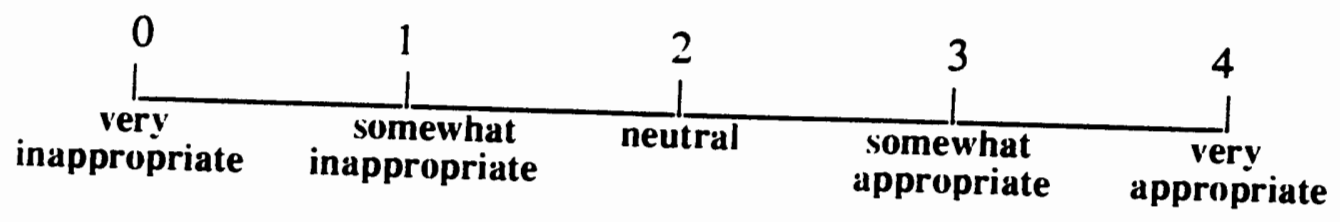

From this picture and the story, you would say your friend is: (Mark one)
[ ] Happy(1)
[] $\operatorname{Sad}(3)$
[ ] Angry(5)
[ ] Afraid(2)
[ ] Surprised(4)
[ ] Disgusted(6)
[ ] (Other, Please fill in) 
2. You're are sitting in class when your teacher begins handing out a midterm examination. You forgot the test is scheduled for today.

Circle the number that corresponds with how appropriate it would be for you to make a face like the one pictured above.

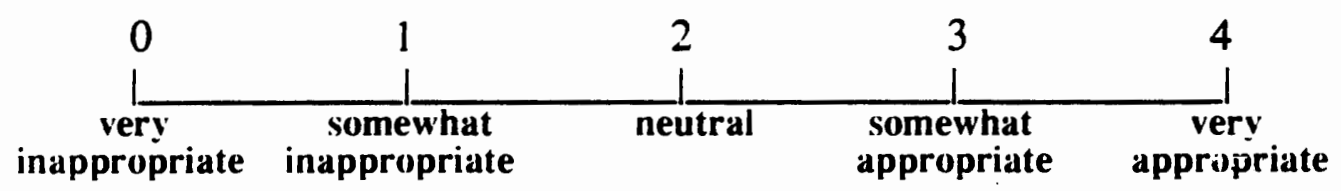

From this picture and the story, you would say you are: (Mark one)
[] Happy(1)
[ ] $\operatorname{Sad}(3)$
[] Angry(5)
[] Afraid(2)
[ ] Surprised(4)
[] Disgusted(6)
[ ] (other, please fill in) 
3. You are playing your favorite sport and have just defeated your opponent.

Circle the number that corresponds with how appropriate it would be for you to make a face like the one pictured above.

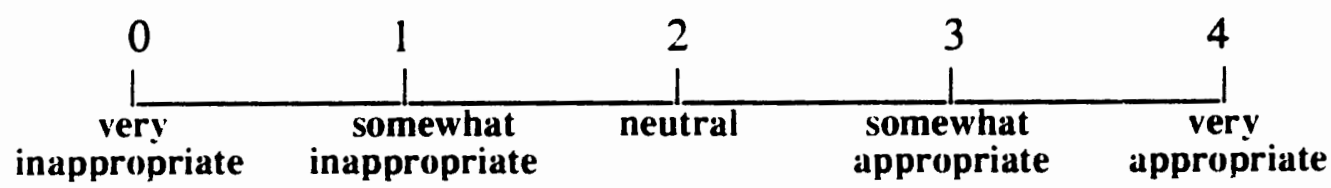

From this picture and the story, you would say you are: (Mark one)
[] Happy(1)
[ ] $\operatorname{Sad}(3)$
[ ] Angry(5)
[ ] Afraid(2)
[ ] Surprised(4)
[ ] Disgusted(6)
[] (other, please fill in) 
Please answer the following questions:

4. How old are you?

[] under 18 (1)

[ ] 18-24 (2)

[ ] 25-35 (3)

[ ] Over 35 (4)
5. In what country were you born?

[ ] United States (1)

[] Japan (2)

[] Canada (3)

[] Other

6. If you are not a native American, how long have you been living in the United States?

[] less than 2 years(2)

[ ] 2 to 4 years(3)

[ ] 4 to 6 years(4)

[] more than 6 years(5)

7. If English is your second language, how many years have you studied the English language?

[] less than 2 years( 2 )

[ ] 2 to 4 years( 3 )

[ ] 4 to 6 years $(4)$

[ ] 6 to 8 years(5)

[] more than 8 years(6)

Thank you very much for your time and cooperation. Your efforts are appreciated! 


\section{APPENDIX C}

PHASE II QUESTIONNAIRE FOR JAPANESE SUBJECTS 
ID \# Survey \#

Picture \#

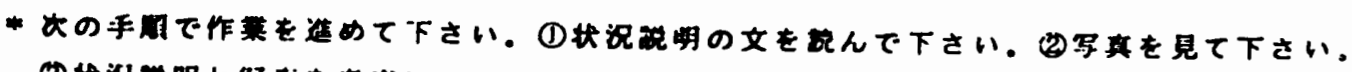

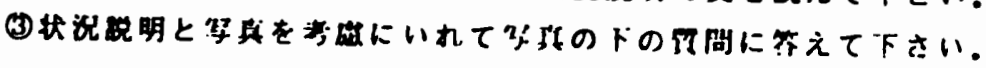

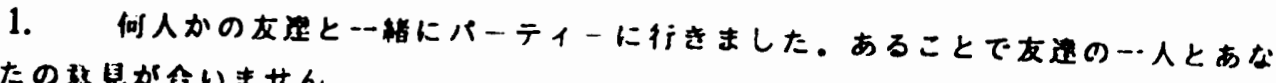
たの見が合いません。

*「この時の友道の願」として上の写真の賏はどのくらい通当だと思いますか。「の 竟㛺を丸で囲んで下さい。

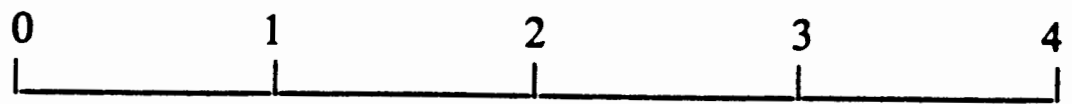

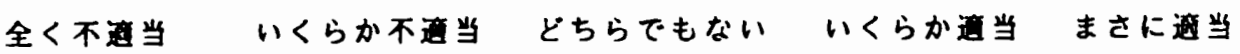

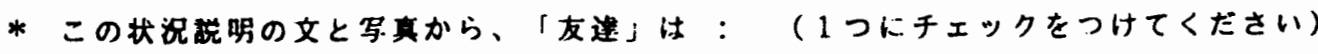

[]来しんでいる(1) [] 悲しんでいる(3) [] 怒っている(5)

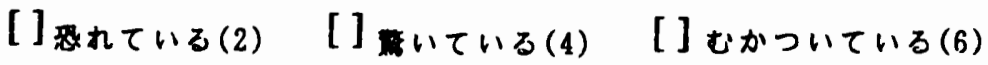

[]その他 （記入して下さい。日本㶾可） 


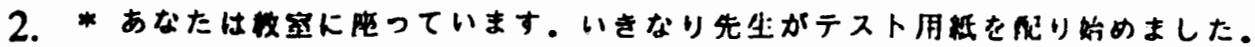
实はあなたは今日テストがあることをすっかり志れていました。

*「この時のあなたの䫄」として上の写直はどのくらい道当だと思いますか，下の番 孯をれで囲んで下さい。

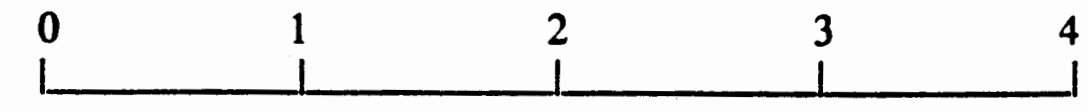

全く不䔔当 いくらか不通当とちらでもないいくらか通当まさに通当

*この状況哷明と写真から「あなた」は：(1つにチェックをつけてください）
[] 来しんでいる(1) []悲しんでいる(3) [] 慗っている(5)

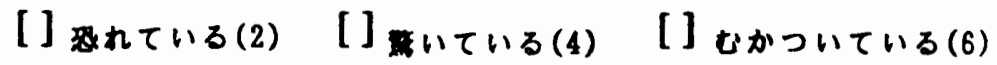

[]その他 (煞入してトさい。甘本䤄可) 


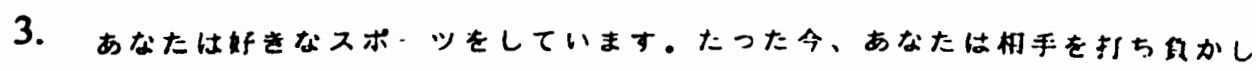
ました。

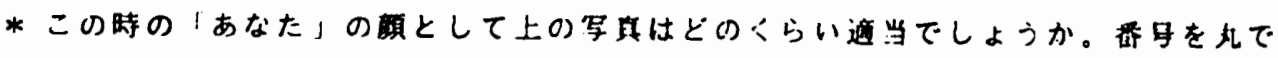
用んで下さい。

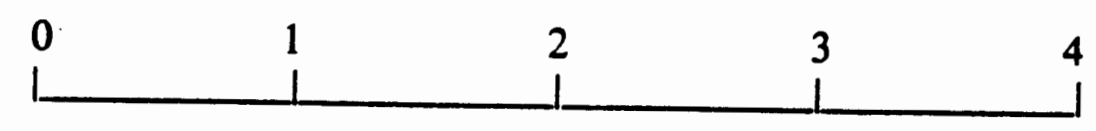

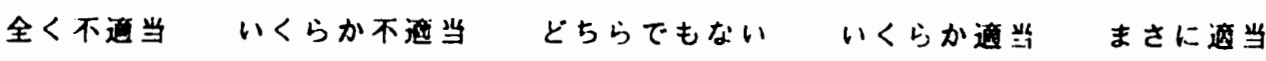

*この状況磁と写朝ら「あなた」は：(1つにチェックをつけてください）
[]楽しんでいる(1) []悲しんでいる(3) [] 怒っている(5)

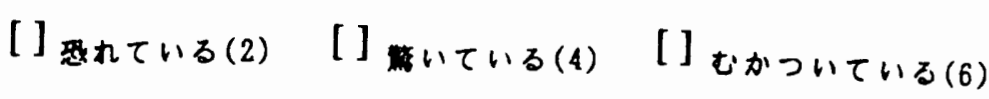
[]その他 (記入して下さい。曰本謤可) 


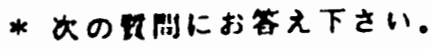

4.あなたの年的は?
[]17お以下(1)
[]18 オから 24 才(2)
[] 25 オから $35 \neq(3)$
[] 36 歹以 (4)

5.出生地の国名は?

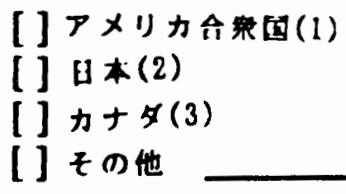

6. 出生地がアメリカ合来国以外の方だけお答え下さい。あなたのアメリカ合承国 の现在までの酒在期間はどのくらいですか？
[] 2 年以下(2)
[] 2 年から 4 年(3)
[] 4 年から 6 年(4)
[] 6 年以上(5)

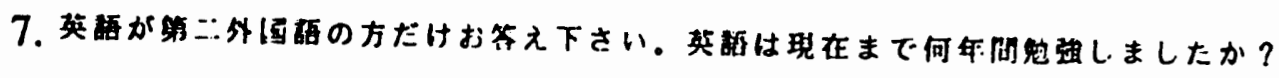
[] 2 年以下
(2)
[] 2 年から 4 年
l]4年から 6 年
[] 6 年から 8 4
[] 8 年以上

*こ協力ありがとっこさいました。 


\section{APPENDIX D}

CAUCASIAN FACIAL EXPRESSION PHOTOGRAPHS 

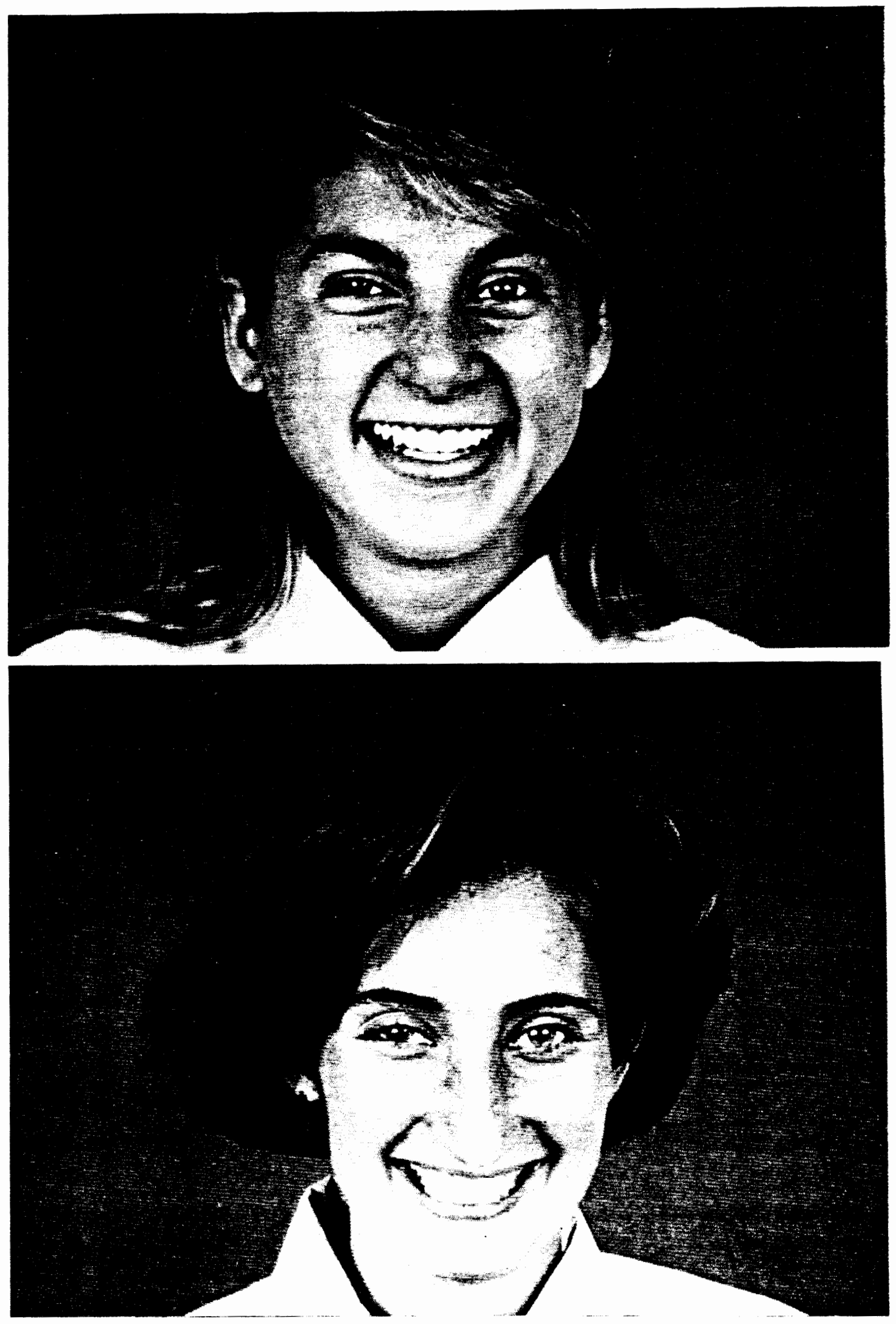


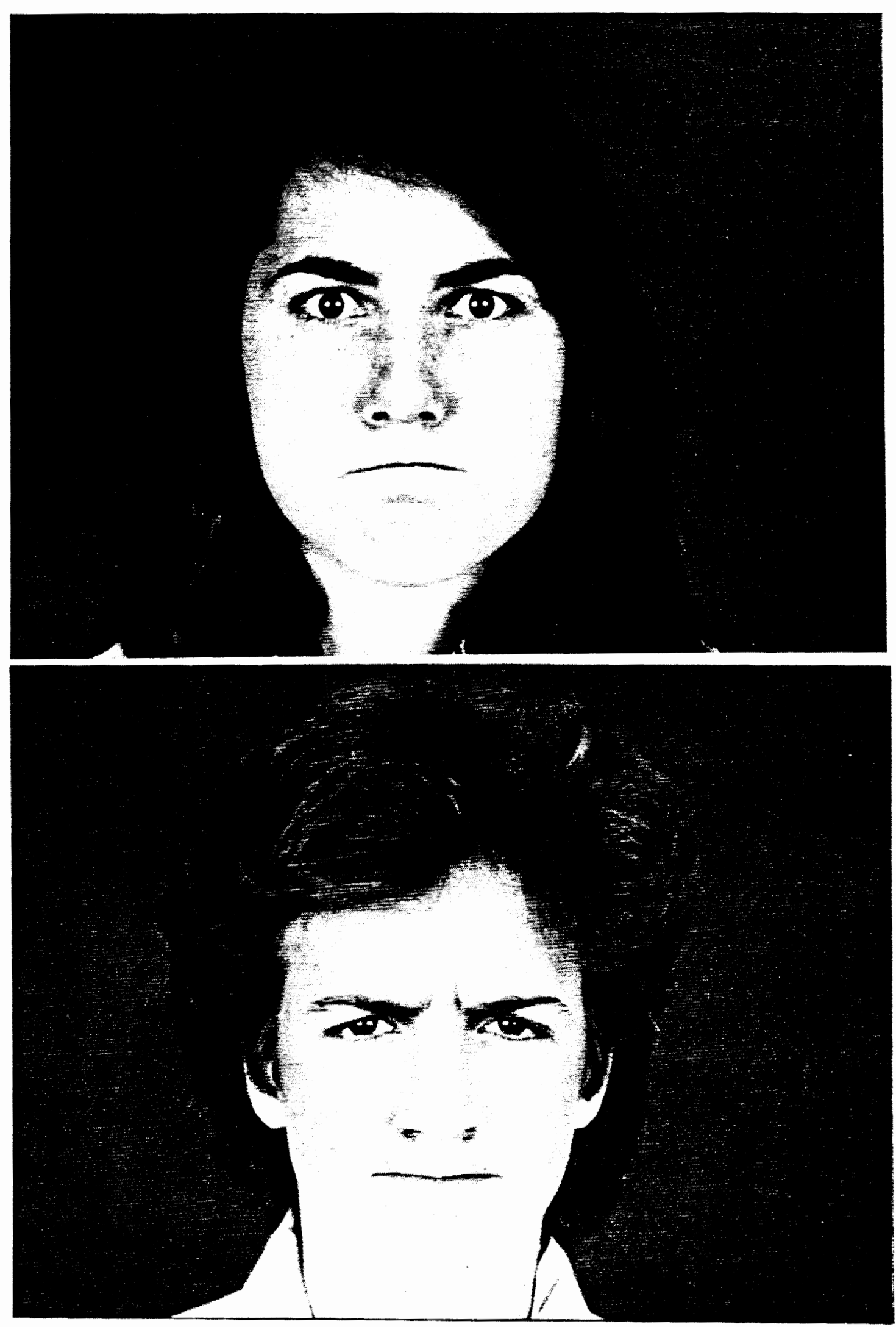




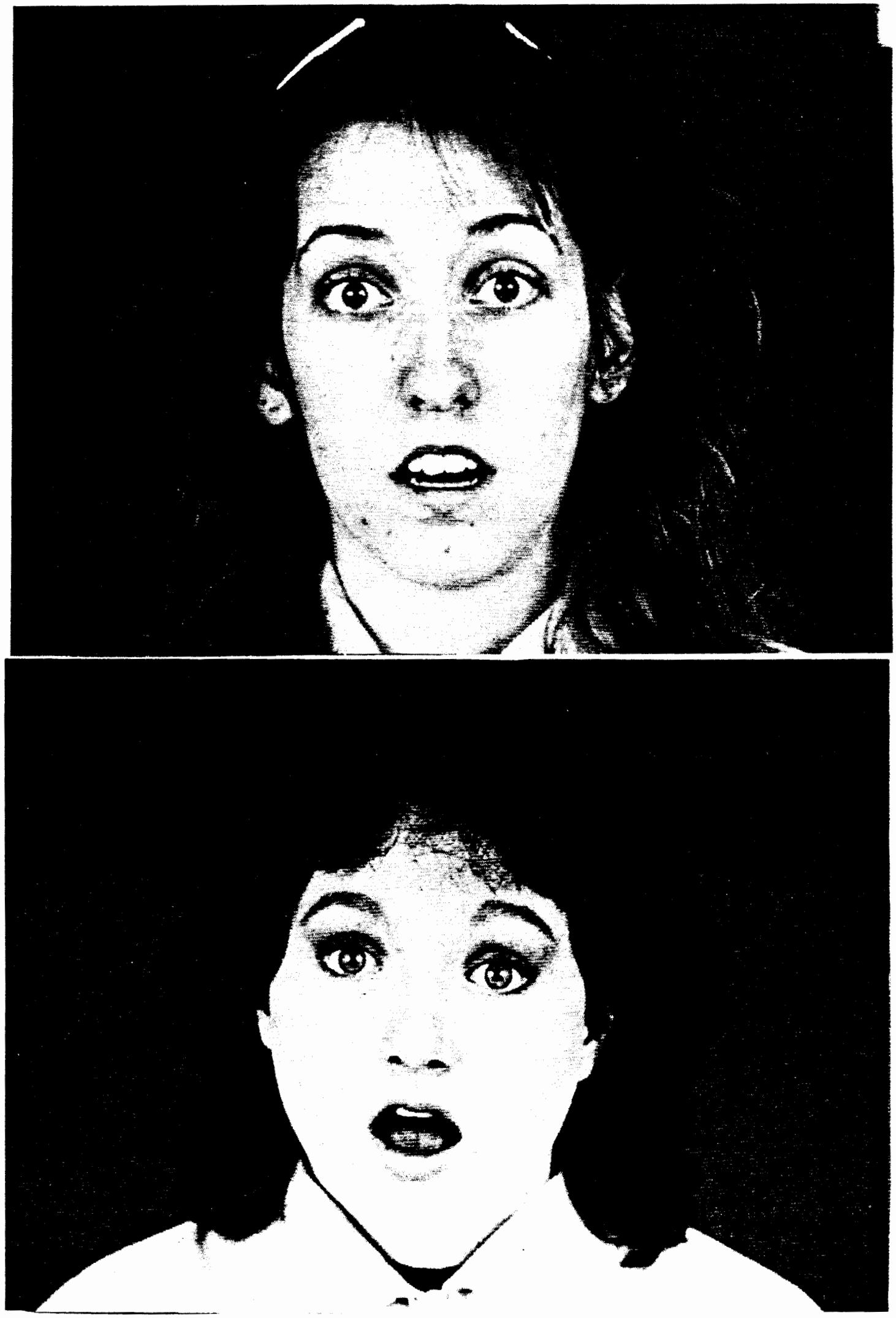




\section{APPENDIXE}

JAPANESE FACIAL EXPRESSION PHOTOGRAPHS 

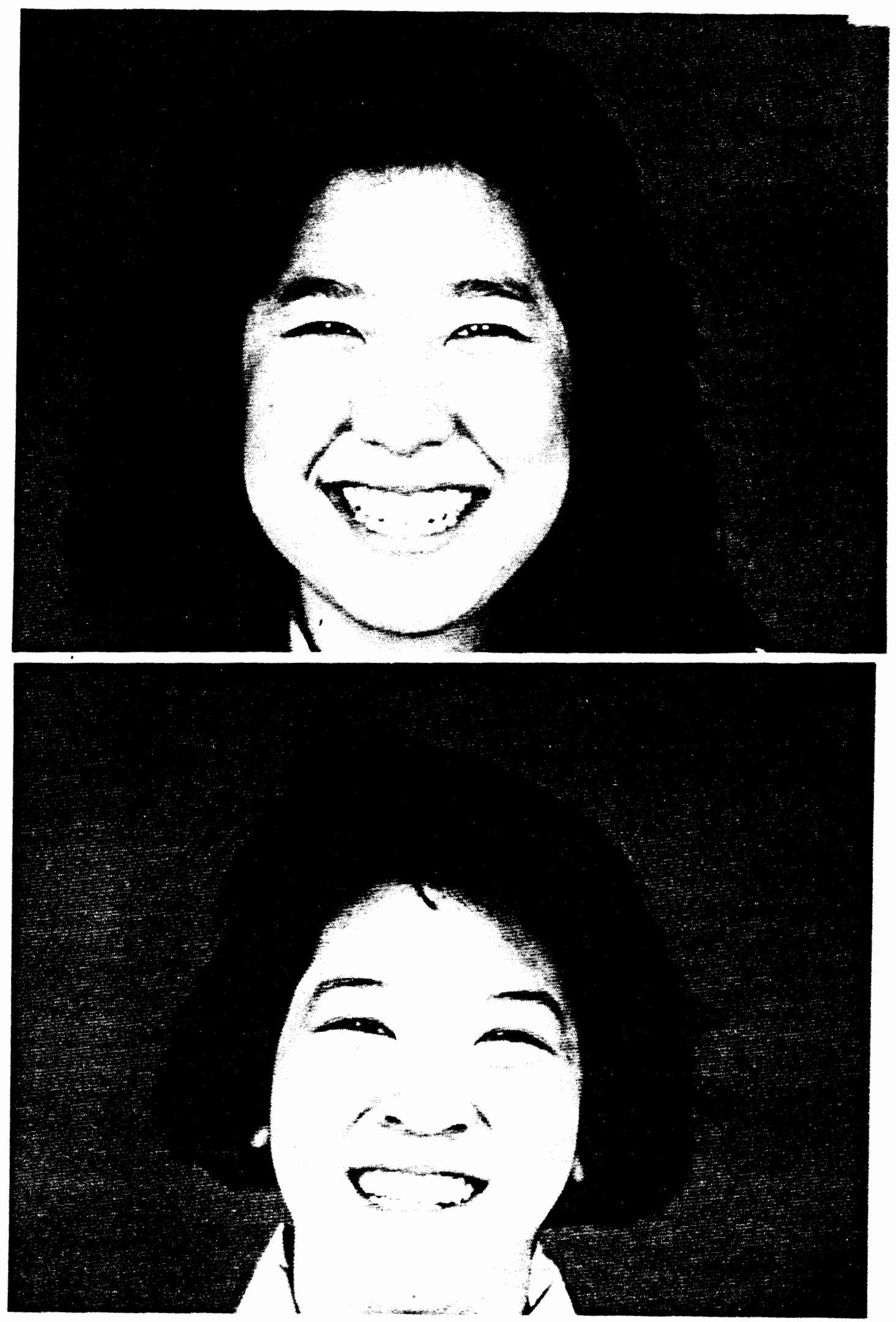

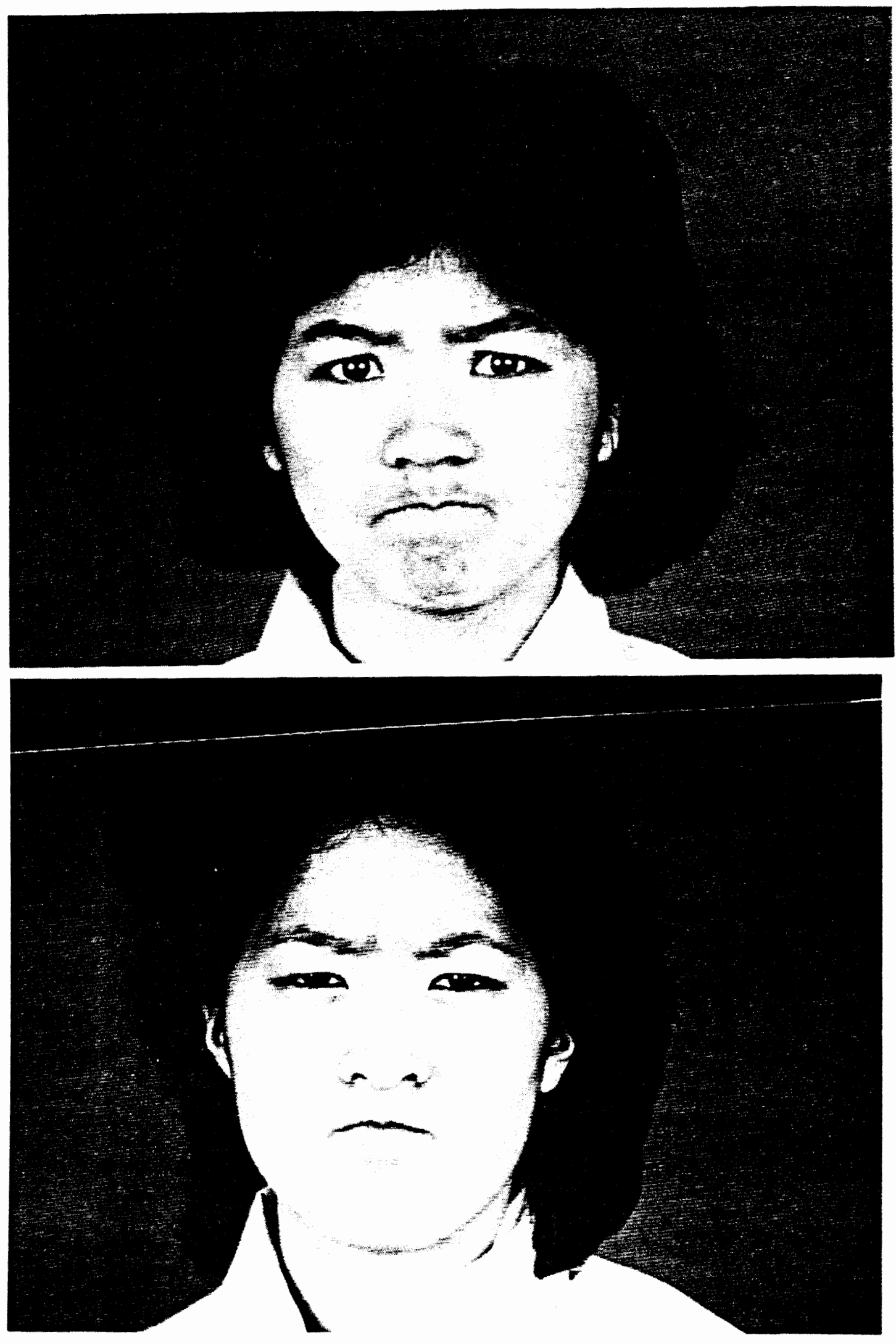

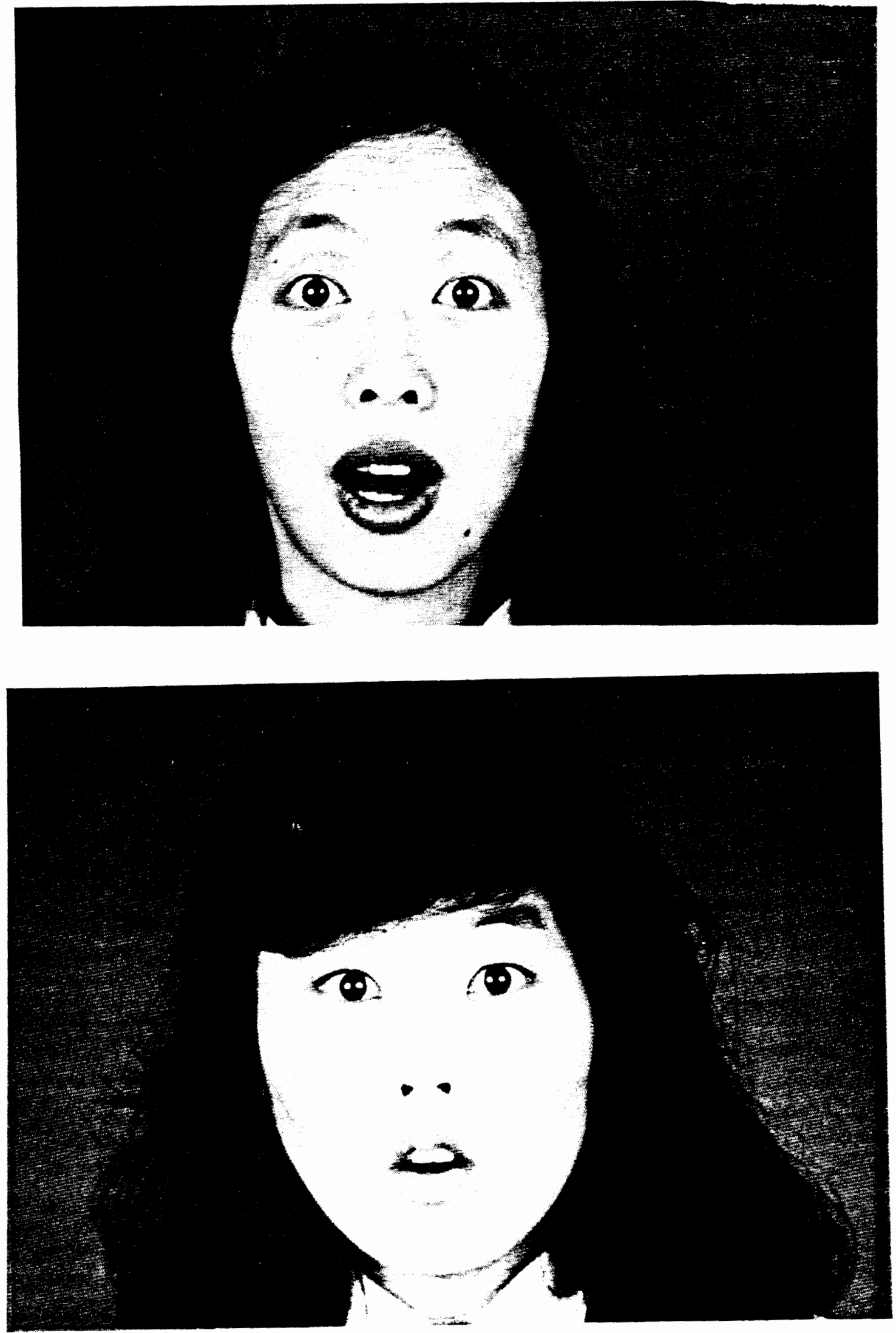